\title{
Effect of Warm SST in the Subtropical Eastern North Pacific on Triggering the Abrupt Change of the Mei-Yu Rainfall over South China in the Early 1990s
}

\author{
YI-KAI WU \\ Department of Earth and Life Sciences, University of Taipei, and Department of Earth Sciences, \\ National Taiwan Normal University, Taipei, Taiwan \\ AN-YI HUANG \\ Department of Earth and Life Sciences, University of Taipei, and National Science and Technology \\ Center for Disaster Reduction, Taipei, Taiwan \\ CHIA-KAI WU AND CHI-CHERNG HONG \\ Department of Earth and Life Sciences, University of Taipei, Taipei, Taiwan \\ CHI-CHUN CHANG \\ Department of Earth and Life Sciences, University of Taipei, and National Science and Technology \\ Center for Disaster Reduction, Taipei, Taiwan
}

(Manuscript received 13 May 2018, in final form 13 August 2019)

\begin{abstract}
In the early 1990s, the mei-yu rainfall over South China in early boreal summer exhibited an abrupt change and northward extension. This change altered the pattern of East Asian summer rainfall from a dipole-like to a monopole-like pattern; that is, the out-of-phase relationship between the rainfall in the south and that in the north of the Yangtze and Huaihe River valley changed to an in-phase relationship. The physical processes potentially responsible for triggering this abrupt change were analyzed in this study. Our observations revealed that the western North Pacific subtropical high (WNPSH), sea surface temperature (SST) in the subtropical eastern North Pacific (SENP), and the mei-yu rainfall in South China exhibited an abrupt increase in the early 1990s, suggesting that these factors are correlated. From the observations and results of numerical experiments, we proposed that the abrupt SST warming in the SENP in the early 1990s generated an east-west overturning circulation anomaly in the Pacific Ocean and that the anomalous downward motion in the western North Pacific consequently triggered the abrupt increase and westward extension of the WNPSH in the early 1990s. The enhanced and westward extension of WNPSH created a low-level southeasterly anomaly that transported considerable humid and warm air into East Asia and sequentially triggered the abrupt increase of mei-yu rainfall in the South China in the early 1990s.
\end{abstract}

\section{Introduction}

The mei-yu front (called baiu in Japanese and changma in Korean) is characterized by a southwest-northeastdistributed rain belt over East Asia and is a special feature of the East Asian summer monsoon (EASM; the definitions of acronyms that are used in this paper are listed in Table 1). The establishment and migration of the mei-yu front are closely associated with the seasonal

Corresponding author: Chi-Cherng Hong, cchong@utaipei.edu. tw; hong0202@gmail.com cycle. The front generally forms in South China, Taiwan, and Okinawa during early summer (May-June), gradually migrates northward to the Yangtze and Huaihe River valley (YHRV) in June-July, and arrives in Korea and northeastern China during late summer (July-August). The mei-yu rainfall, which accounts for approximately $50 \%-70 \%$ of the total annual rainfall in East Asia, presents complex spatial and temporal structures in seasonal cycle (Tao and Chen 1987), interannual variability (Ding et al. 2008; Zhu et al. 2014), and interdecadal fluctuation (Chang et al. 2000; Kwon et al. 2007; Yim et al. 2008a). 
TABLE 1. Definition of abbreviation used in this paper.

\begin{tabular}{ll}
\hline \hline Abbreviation & \multicolumn{1}{c}{ Definition } \\
\hline EASM & East Asian summer monsoon \\
SENP & subtropical eastern North Pacific \\
IO & Indian Ocean \\
MFC & moisture flux convergence \\
RSI & regime-shift index \\
TNA & tropical North Atlantic \\
WNP & western North Pacific \\
WNPSH & WNP subtropical high \\
YHRV & Yangtze and Huaihe River valley \\
\hline
\end{tabular}

Studies have revealed that the mei-yu rainfall over South China and Taiwan exhibited an interdecadal change in the early to middle 1990s (Chan and Zhou 2005; R. Wu et al. 2010; Yim et al. 2008b, 2014), and this change was attributed to the enhancement of the western North Pacific subtropical high (WNSPH). The WNPSH is characterized by an anomalous anticyclone over the western North Pacific (WNP) in the lower troposphere, which significantly modulates the EASM system at multiple time scales. The mei-yu rainfall in South China and the YHRV is expected to increase with an enhancement of the WNPSH. The WNPSHassociated southeasterly anomaly transports humid and warm air into East Asia, thus causing a rainfall surplus (He and Zhou 2014; Li et al. 2012). Although sea surface temperature (SST) forcing in various basins, such as the Indian Ocean (IO) (Yang et al. 2007; Zhou et al. 2009; Xie et al. 2009, 2010; B. Wu et al. 2010; Zhang et al. 2017), Atlantic Ocean (Hong et al. 2014; Sun et al. 2017), and central Pacific Ocean (Yim et al. 2014), contributes substantially to WNPSH enhancement, the temporal evolution of the SSTs in these regions did not exhibit an abrupt (rapid) change in the early 1990s. This suggests that the SST anomalies in these regions were unlikely to have triggered the abrupt change in the WNPSH in the early 1990s.

A prominent feature of the interdecadal variation of the EASM rainfall is the negative correlation between the rainfall in the south and that in the north of the YHRV; specifically, a rainfall surplus occurs in South China, while a rainfall decline occurs in the north or YHRV (and vice versa). In this study, we demonstrated that the out-of-phase relationship was clearly identified before the 1990s; however, the out-of-phase relationship changed suddenly to an in-phase relationship since the early 1990s (Fig. 1). A preliminary study revealed that this change was potentially caused by the interdecadal northward extension of the mei-yu rainfall in the early 1990s.

The EASM includes premonsoon (May-June) and postmonsoon (July-August), in which the associated interannual and interdecadal variations exhibit distinct features in many aspects (Wang and Lin 2002; Yim et al. 2014). Whereas the interdecadal change of EASM in the whole summer (June-August) in the early 1990s had been noted for a while (e.g., R. Wu et al. 2010; Zhang et al. 2017, 2018), the physical processes responsible for the interdecadal change in the mei-yu (May-June) rainfall in the early 1990s was not thoroughly investigated. Recently, Yim et al. (2014) proposed that the leading mode of interannual variation in East Asian rainfall in the premonsoon season changed from a dipole-like to a tripole-like pattern since the mid-1990s because of the combined effects of the warm SST anomaly (SSTA) in the equatorial central Pacific and the tripolar SSTAs in the North Atlantic. Yim et al. (2014) analyzed the distinctive features of the interannual fluctuation of the mei-yu rainfall during different episodes (pre- and post-1995); however, the physical processes responsible for the interdecadal change in the mei-yu rainfall in the early 1990s were not discussed in their study.

This study proposes a possible mechanism that may have triggered the abrupt change in the WNPSH and mei-yu rainfall in South China in the early 1990s. The abrupt change in the SST in the subtropical eastern North Pacific (SENP) and enhancement of the WNPSH in the early 1990s suggest that these factors might be correlated. We hypothesized that the warm SENP-SSTassociated convection anomaly forced an east-west overturning circulation anomaly in the Pacific Ocean and that the subsidence in the western Pacific may have subsequently triggered the abrupt increase and westward extension of the WNPSH in the early 1990s, which subsequently caused the mei-yu rainfall in South China to extend northward to the YHRV.

\section{Data and methods}

The dataset included the following: 1) European Centre for Medium-Range Weather Forecasts reanalysis atmospheric dataset for 1958-2002 (Uppala et al. 2005); 2) Hadley Centre Sea Ice and Sea Surface Temperature dataset for 1958-2013 (Rayner et al. 2003); 3) Climatic Research Unit (CRU) Time Series, version 3.20 (Jones and Harris 2013), precipitation data for 1951-2012; 4) Global Precipitation Climatology Project, version 2.2 (Adler et al. 2003; Huffman et al. 2009); 5) Asia Precipitation-Highly Resolved Observational Data Integration Toward Evaluation (APHRODITE; Yatagai et al. 2012) high-resolution daily precipitation data for 1951-2007. The Student's $t$ test was used to assess the statistical significance of the differences between the composite in two distinct time periods. A 7-yr running 
(a) $1951 \sim 2012\left(105-122^{\circ} \mathrm{E}\right)$ Precipitation ( $\left.y r=7\right)$ (MAY)

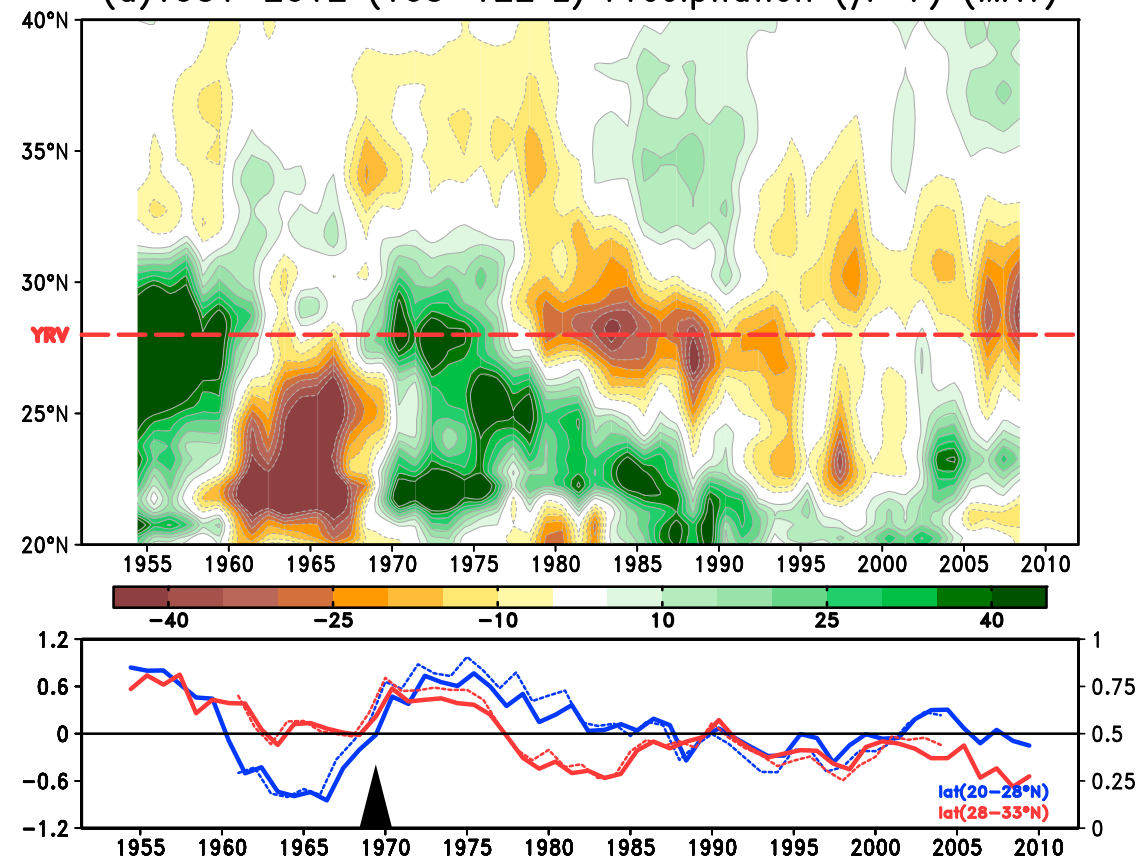

(b) 1951 2012 (105-122 E) Precipitation (yr=7) (JUN)

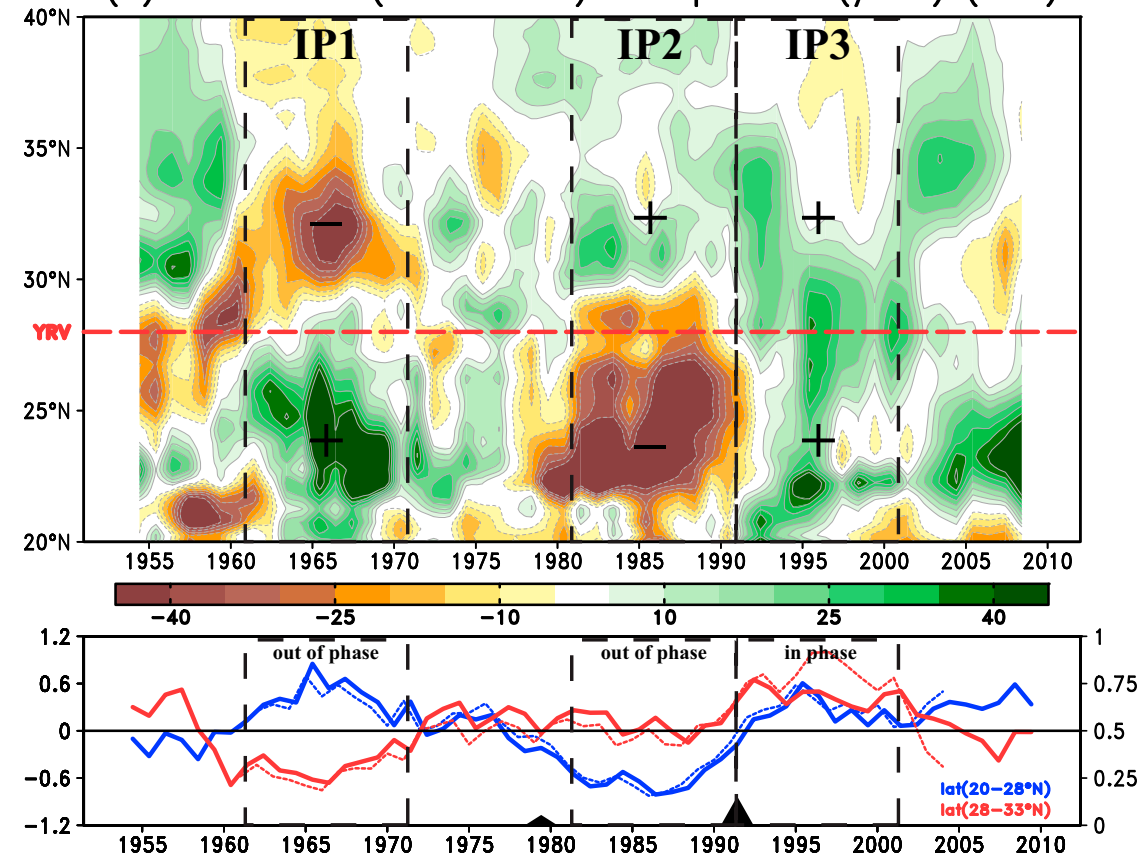

FIG. 1. Hovmöller diagram (averaged over $\left.105^{\circ}-122^{\circ} \mathrm{E}\right)$ of interdecadal variation (7-yr running mean) anomaly of CRU $0.5^{\circ} \times 0.5^{\circ}$ precipitation (mm) in (a) May and (b) June for 1951-2012. On the basis of the interdecadal variation of the mei-yu rainfall in June in (b), the time evolution of rainfall is separated into three interdecadal periods, IP1 (1962-72), IP2 (1982-92), and IP3 (1992-2002). The blue and red lines in the bottom of (a) and (b) indicate the rainfall anomaly in South China $\left(20^{\circ}-28^{\circ} \mathrm{N}\right)$ and the YHRV $\left(28^{\circ}-33^{\circ} \mathrm{N}\right)$, respectively. The dashed lines shown indicate the time series of rainfall in South China and the YHRV from the APHRODITE dataset (Yatagai et al. 2012). The black triangles show the calculated RSI (Rodionov 2004) of the unfiltered rainfall anomaly in South China. Details of RSI were documented in section 2. The $Y$ axes on the left and right of the bottom of (a) and (b) denote the rainfall and RSI, respectively. 
mean, closely fitting the 8-yr Lanczos low-pass filter (Duchon 1979), was used to isolate the interdecadal signal. A regime-shift index (RSI; Rodionov 2004) of unfiltered data was used to identify the specific time at which the time series experienced a significant abrupt change. Here, an abrupt change means a time-mean (10-yr mean) state shifts to another time-mean state in a relatively short time in comparison with the duration of time-mean period. A cutoff length of $10 \mathrm{yr}$ was used in changepoint calculation, and only RSI values that met the 0.05 significance level requirement were considered. Bayesian analysis (Barry and Hartigan 1993; Erdman and Emerson 2008) was also used to identify the mei-yu rainfall changepoint. The RSI and Bayesian analysis results were consistent.

The vertically integrated moisture flux can be calculated using the following equation:

$$
\left\langle q \mathbf{V}_{h}\right\rangle=-\frac{1}{g} \int_{300}^{\mathrm{ps}}\left(q \cdot \mathbf{V}_{h}\right) d p .
$$

In the equation, $\mathbf{V}_{h}=(u, v), q$ is the specific humidity, $g$ is the gravitational constant, and ps is the pressure at the surface. The angle brackets represent a vertically integrated quantity. The moisture budget for an air parcel can be expressed as follows:

$$
\begin{aligned}
\langle P\rangle-\langle E\rangle= & -\underbrace{\frac{1}{g} \int_{300}^{\mathrm{ps}} \frac{\partial q}{\partial t} d p}_{\mathrm{A}}-\underbrace{\frac{1}{g} \int_{300}^{\mathrm{ps}} \nabla\left(q \cdot \mathbf{V}_{h}\right) d p}_{\mathrm{B}} \\
& -\underbrace{\frac{1}{g} \int_{300}^{\mathrm{ps}} \frac{\partial}{\partial p}(q w) d p}_{\mathrm{C}},
\end{aligned}
$$

where $\nabla=\hat{i}(\partial / \partial x)+\hat{j}(\partial / \partial y)$ and $E$ and $P$ represent the evaporation and precipitation rates, respectively. Term A indicates the local rate of the change of $q$; terms B and C indicate the horizontal and vertical moisture flux convergence (MFC), respectively. Because the observed amplitude of $E$ was much lower than that of $P$ and the right-hand terms in Eq. (2) were dominated by the horizontal MFC (not shown), the equation was approximate to

$$
\langle P\rangle \simeq-\frac{1}{g} \int_{300}^{\mathrm{ps}} \nabla \cdot\left(q \cdot \mathbf{V}_{h}\right) d p
$$

\section{Observational analysis}

a. Abrupt northward extension of the mei-yu rainfall in the early 1990s

Figure 1 depicts the Hovmöller diagram (averaged over $105^{\circ}-122^{\circ} \mathrm{E}$ ) for the interdecadal (7-yr running mean) fluctuation of precipitation in the mei-yu season
(May-June). The rainfall intensity in May over South China $\left(20^{\circ}-28^{\circ} \mathrm{N}\right.$; blue line at the bottom of Fig. 1a) presented an interdecadal variation before 1980; specifically, the rainfall was below normal during 1960-70 but was above normal during 1970-80 (Fig. 1a). The time series of rainfall over South China clearly demonstrated an abrupt increase approximately in 1970 (dark black triangle in Fig. 1a). Notably, the interdecadal fluctuation of the mei-yu rainfall in May was below normal since 1980 (Xin et al. 2006), but it did not exhibit an abrupt change in the early 1990s. Conversely, the interdecadal variation of rainfall in June was clearly identified throughout the assessed period (Fig. 1b). The rainfall over South China in June was above normal during the 1960s and 1990s but was below normal in the 1980s (Fig. 1b). The spatial distribution of precipitation in June reflected a classic dipole-like structure of southern flooding and northern drought during the 1960s, but an opposite structure was observed in the 1980s (Yu and Zhou 2007). During the 1990s, the precipitation pattern over South China was similar to that in the 1960 s, but the mei-yu rainfall extended significantly northward from South China to the YHRV. Additionally, a negative rainfall anomaly over Vietnam, Myanmar, and Cambodia was observed in 1992-2002 (referred to as IP3), which was opposite to that in 1962-72 (referred to as IP1). Time series of rainfall over South China $\left(20^{\circ}-28^{\circ} \mathrm{N}\right.$; blue line in Fig. $\left.1 \mathrm{~b}\right)$ and over the YHRV $\left(28^{\circ}-33^{\circ} \mathrm{N}\right.$; red line in Fig. 1b) revealed that rainfall in South China and that in the YHRV were out of phase during the 1960s and 1980s. However, this out-ofphase relationship changed suddenly to an in-phase relationship in the early 1990s. An RSI calculation further revealed that the mei-yu (June) rainfall in South China exhibited a significantly abrupt change in approximately 1992, 1-2 years earlier than the abrupt change of whole summer (June-August) 1992-93 (R. Wu et al. 2010; Zhang et al. 2018). Because the magnitude of interdecadal variation of mei-yu rainfall in May was weaker than that in June and it did not exhibit an abrupt change in the early 1990s, we focused on the interdecadal change of the mei-yu rainfall in June. As shown in Fig. 1b, the mei-yu rainfall over South China in June was divided into three interdecadal periods (IPs), namely, IP1 (1962-72), IP2 (1982-92), and IP3 (1992-2002). IP1 and IP2 exhibited the canonical structure of the EASM, namely, the out-of-phase relationship between the rainfall in South China and that in the YHRV. This dipole-like rainfall pattern changed to a monopole-like structure during IP3.

\section{b. Moisture flux analysis}

Figure 2 presents the anomalous rainfall (shaded), 850-hPa horizontal wind, and the WNPSH (contour of $1525 \mathrm{~m}$ geopotential height) during IP1, IP2, and IP3. As 
(a) IP1 rainfall \& 850-uv anomalies (June)

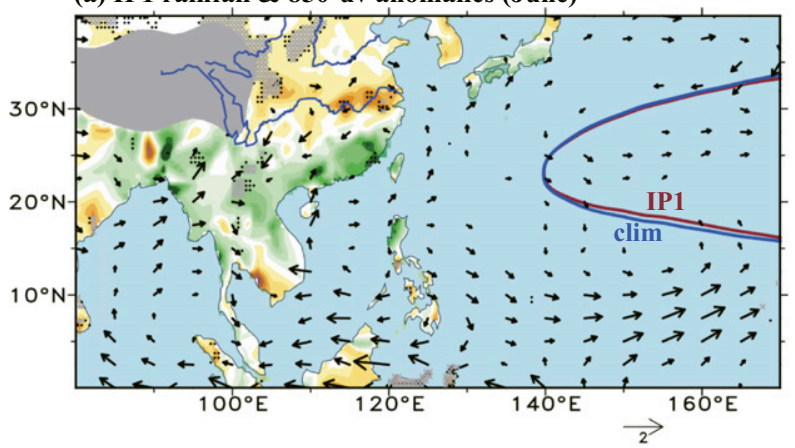

(b) IP2 rainfall \& 850-uv anomalies (June)

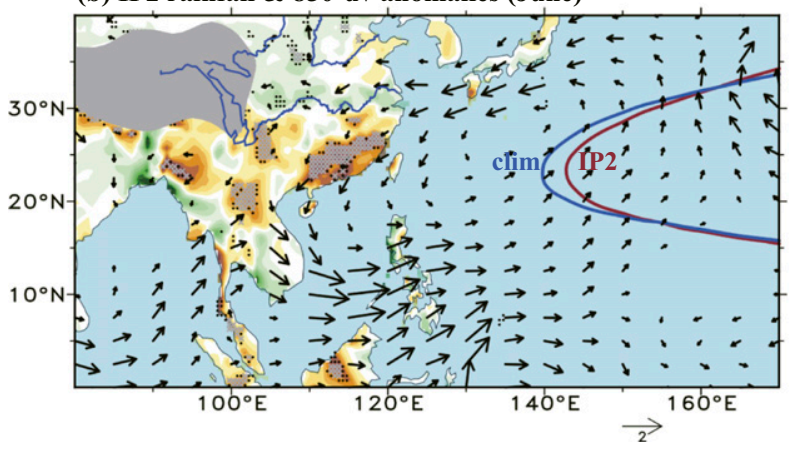

(c) IP3 rainfall \& 850-uv anomalies (June)

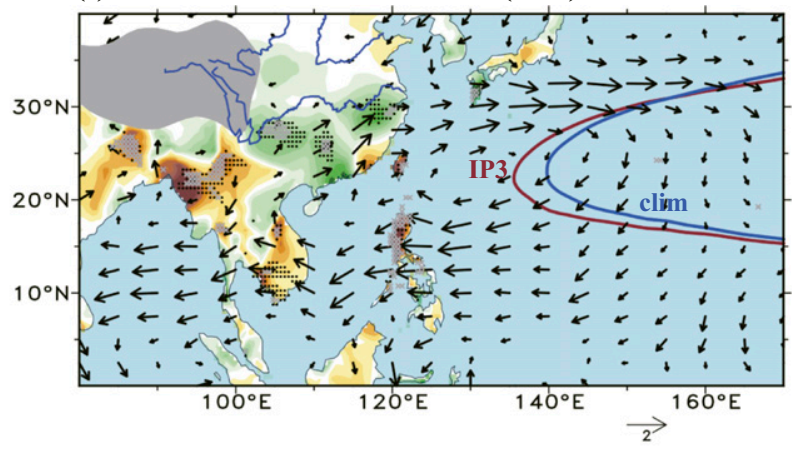

(d) IP3-IP1 rainfall \& 850-uv anomalies (June)

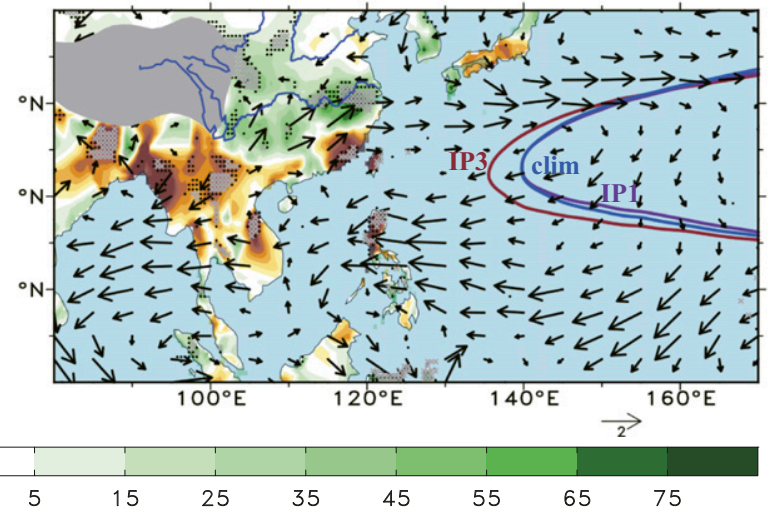

FIG. 2. The anomalous 850-hPa wind (vectors) and rainfall (shading) in June for the periods of (a) IP1, (b) IP2, and (c) IP3, along with (d) IP3 minus IP1. The red and blue contours represent $1525 \mathrm{~m}$ of geopotential height of the period and climatology, respectively. The black dots and gray cross hatching) show the result at confidence levels of $90 \%$ and $95 \%$, respectively. Only wind speed larger than $0.4 \mathrm{~m} \mathrm{~s}^{-1}$ was plotted.

shown in this figure, the rainfall surplus over South China during IP1 was associated with an enhanced southwesterly monsoon flow that originated from the IO (Fig. 2a). The enhanced monsoon flow resulted in a meridionally distributed rainfall surplus, moving eastward from Myanmar and Laos to South China. Conversely, a decrease in rainfall was observed in the YHRV and north of the YHRV. During IP2, a pronounced cyclone-like circulation anomaly was observed over East China (Fig. 2b). The large-scale anomalous cyclone-associated northeasterly anomaly substantially reduced the southwesterly monsoon flow and sequentially resulted in a rainfall decline in South China during IP2. By contrast, an anticyclonic circulation anomaly was identified over the western subtropical Pacific and South China Sea during IP3 (Fig. 2c). The anticyclone anomaly-associated southeasterly anomalies in the WNP transported considerable volumes of warm and moist maritime air to the continent, which resulted in a rainfall surplus over South China and the YHRV. Figure 2 clearly depicts that the WNPSH was enhanced and exhibited a westward extension during IP3. Comparing IP1 and IP3 (Fig. 2d) clearly revealed that the mei-yu rainfall extended northward to the YHRV during IP3. The Hovmöller diagram (averaged over $105^{\circ}-$ $122^{\circ} \mathrm{E}$ ) of pentad precipitation further indicated that this northward shift was accompanied by a northward extension of the mei-yu front (figure not shown).

A moisture flux budget was applied over South China and the YHRV (the dashed black box in Fig. 3c), where a pronounced MFC anomaly occurred, to investigate the specific water vapor source responsible for the mei-yu rainfall surplus in South China and the YHRV during IP3. The investigation revealed that the northward moisture flux from the south $\left(25^{\circ} \mathrm{N}\right)$ of the bulk region increased by approximately $18 \%$ (from 99 to 117 units) during IP3 when compared with climatology (1960-2000). However, the meridional moisture flux in the north $\left(33^{\circ} \mathrm{N}\right)$ was almost unchanged (remaining at 14 units) during IP3 relative to climatology. Specifically, the northward moisture flux from the southern edge of the bulk region resulted in a pronounced net 
(a)

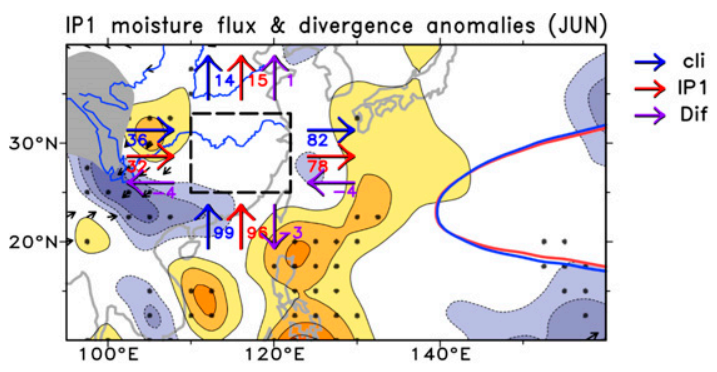

(b)

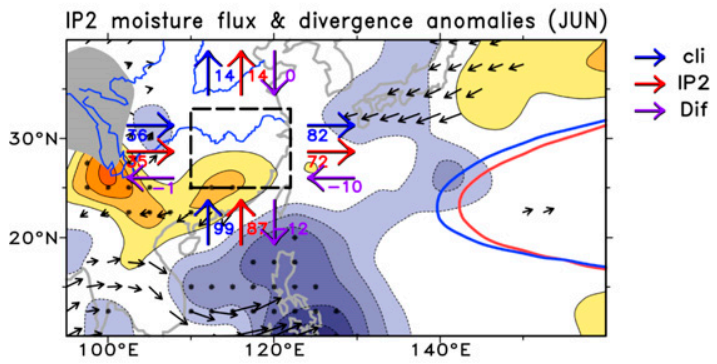

(c)

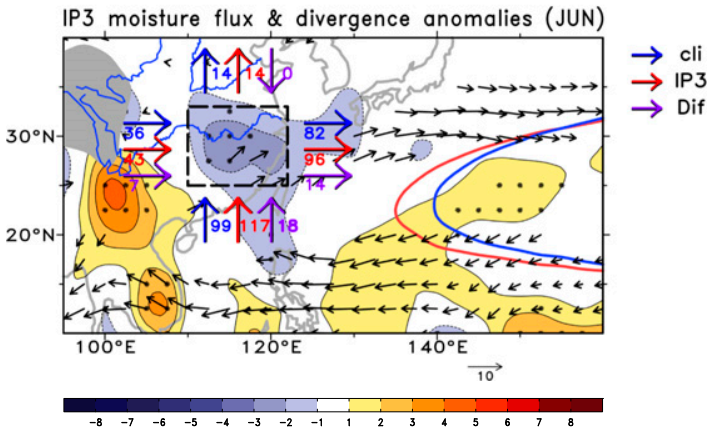

FIG. 3. The vertically integrated (from the surface to $300 \mathrm{hPa}$ ) moisture fluxes $\left(10^{-4} \mathrm{~g} \mathrm{~m}^{-1} \mathrm{~s}^{-1}\right)$ and moisture fluxes divergence $\left(10^{2} \mathrm{~g} \mathrm{~m}^{-2} \mathrm{~s}^{-1}\right)$ over South China and the YHRV (the dash-outlined boxes) in June in (a) IP1, (b) IP2, and (b) IP3. The shading shows a nine-point smoothing to the gridded result. The numbers shown on the boundary of the boxes indicate the moisture flux in or out of the box. The boxes, including South China and YHRV, were chosen as where significant moisture flux convergence was identified. They show that the net northward moisture flux resulted in a pronounced moisture flux convergence in IP3. The red and blue contours are $1525 \mathrm{~m}$ of geopotential height in IP3 and climatology, respectively. Shading with dots and black arrows indicate exceeding $95 \%$ and $90 \%$ confidence levels, respectively.

MFC in South China and the YHRV. Different from the meridional moisture flux, a net zonal moisture flux divergence (from 7 to 14 units) over South China and the YHRV was observed during IP3; the magnitude of zonal moisture flux (7 units) was smaller than that of the net meridional flux (18 units). The moisture budget clearly revealed that the surplus and northward extension of the mei-yu rainfall in South China and the YHRV during the
IP3 epoch was primarily caused by the enhancement of the meridional moisture flux in South China.

In contrast to IP3, the pronounced northward moisture flux and MFC in the YHRV were not observed during IP1 or IP2 (Figs. 3a,b). This difference indicates that the interdecadal above-normal rainfall in South China during IP1 and IP3 was attributed to distinct physical processes, namely, the enhanced southwesterly Indian monsoon flow and anomalous southeasterly in the western WNP (in response to the enhanced WNPSH), respectively (Figs. 2c and 3a).

\section{c. Time-mean state change in IP3 (1992-2002)}

Figure 4 depicts the atmospheric and oceanic background changes during IP3. A meridionally oriented low-level wave train, an anomalous anticyclone in the WNP, and a cyclone anomaly in the south of the WNP (over the "Maritime Continent") and north of the WNP (Japan) were observed in East Asia (Figs. 4a,b). The pattern of the anticyclone and cyclone anomalies in the WNP and Japan resembled the Pacific-Japan pattern (Nitta 1987). Considerable warming in various ocean basins, including the WNP, tropical IO, tropical North Atlantic (TNA), and SENP, was determined (Fig. 4a). Notably, the high negative SSTA in the North Pacific was not significant because of the high variance of SST in the North Pacific. In the west and east of the WNP anticyclone (centered at approximately $135^{\circ} \mathrm{E}$, Fig. 4b), positive and negative SSTAs, respectively, were observed, suggesting that the air-sea interaction contributes to the maintenance of the WNP anticyclone (Wang et al. 2000). Among the mean background changes, the respective large-scale positive and negative rainfall anomaly in the SENP and WNP were particularly prominent (Fig. 4b). The zonal dipole-like rainfall anomaly was associated with ascending and descending anomalies in the SENP and WNP, respectively, forming an east-west overturning circulation in the Pacific (Figs. 4c,d). In addition, a significant ascending anomaly was clearly observed in the IO. The ascending and descending anomalies in the IO and WNP, respectively, created a southwest-northeast overturning circulation anomaly in the IO-WNP, which may enhance the WNPSH (R. Wu 2010; B. Wu 2010).

\section{d. Large-scale factors associated with the abrupt change in the early 1990s}

As shown in Fig. 4, the SSTs in the IO, SENP, and TNA as well as the WNPSH index were plotted to investigate the possible relationships between these largescale factors and the mei-yu rainfall in South China. The plots showed that the SENP-SST, mei-yu rainfall in South China, and WNPSH exhibited an abrupt change 

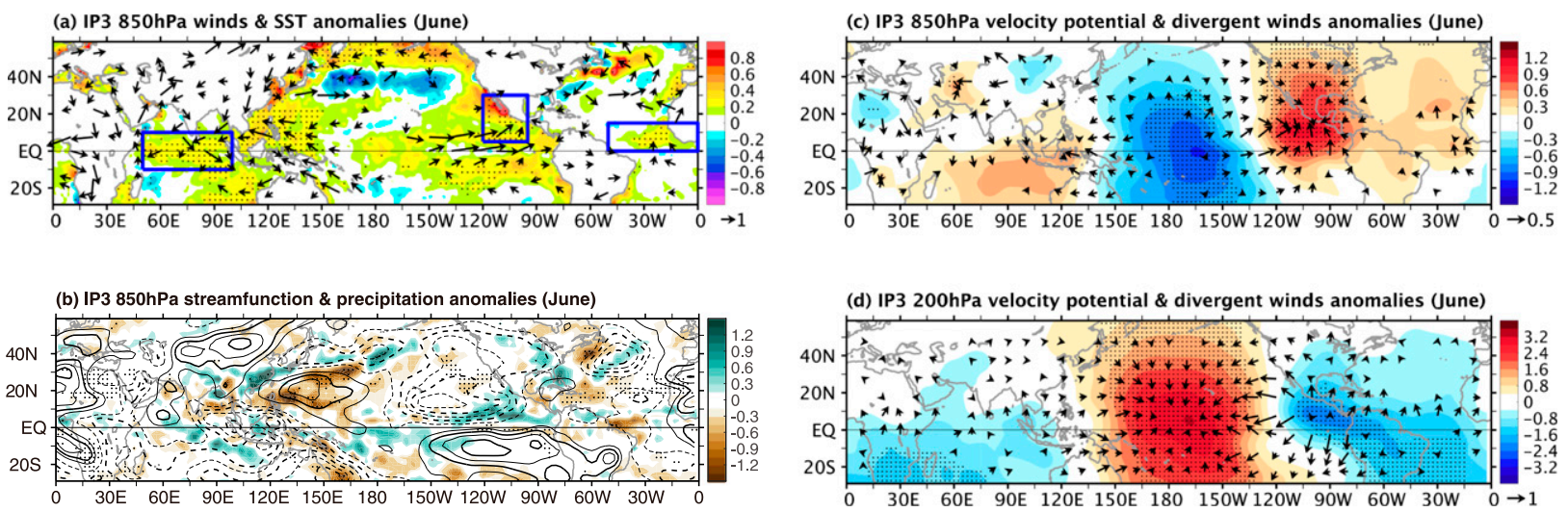

FIG. 4. Anomalous fields in June during IP3 (1992-2002) for (a) SST (shading; ${ }^{\circ} \mathrm{C}$ ) and 850-hPa wind (vectors; $\mathrm{m} \mathrm{s}^{-1}$ ), (b) precipitation (shading; $\mathrm{mm}$ ) and $850-\mathrm{hPa}$ streamfunction (contours; $10^{-6} \mathrm{~m}^{2} \mathrm{~s}^{-1}$ ), and (c) 850 - and (d) 200-hPa velocity potential (shading; $10^{-6} \mathrm{~m}^{2} \mathrm{~s}{ }^{-1}$ ) and divergent wind. Shading with dots indicates significance exceeding the $95 \%$ confidence level. The blue-outlined boxes in (a) indicate the specific SSTA prescribed to the model in the numerical experiments. Only wind speeds exceeding $0.5,0.15$, and $0.2 \mathrm{~m} \mathrm{~s}^{-1}$ for (a) $-(\mathrm{c})$, respectively, were plotted.

in the early 1990s (Fig. 5). Whereas the SSTs in the IO may have enhanced the WNPSH (Chang et al. 2016; Hong et al. 2015; B. Wu et al. 2010; Yang et al. 2007), they had started warming in the late 1970s. Additionally, no changepoint in the early 1990s was detected for the IO-SST and TNA-SST. Note that the abrupt change of TNA-SST in 1995 was associated with the phase change of the Atlantic multidecadal oscillation (AMO) in the mid-1990s (Enfield et al. 2001), which was 3-4 years later than the abrupt change of mei-yu rainfall in 1991-92.
This indicates that the SSTs in the IO and TNA were unlikely to have triggered the abrupt increase in the WNPSH in the early 1990s. Other climate indices, such as the Pacific decadal oscillation or interdecadal Pacific oscillation, which exhibited substantial influences on the EASM (e.g., Ma 2007; Qian and Zhou 2014), were also investigated. No significant abrupt change in the early 1990s was detected, indicating the unique relationship between the WNPSH and SENP-SST in the early 1990s. Calculating the monthly lead-lag correlation coefficient

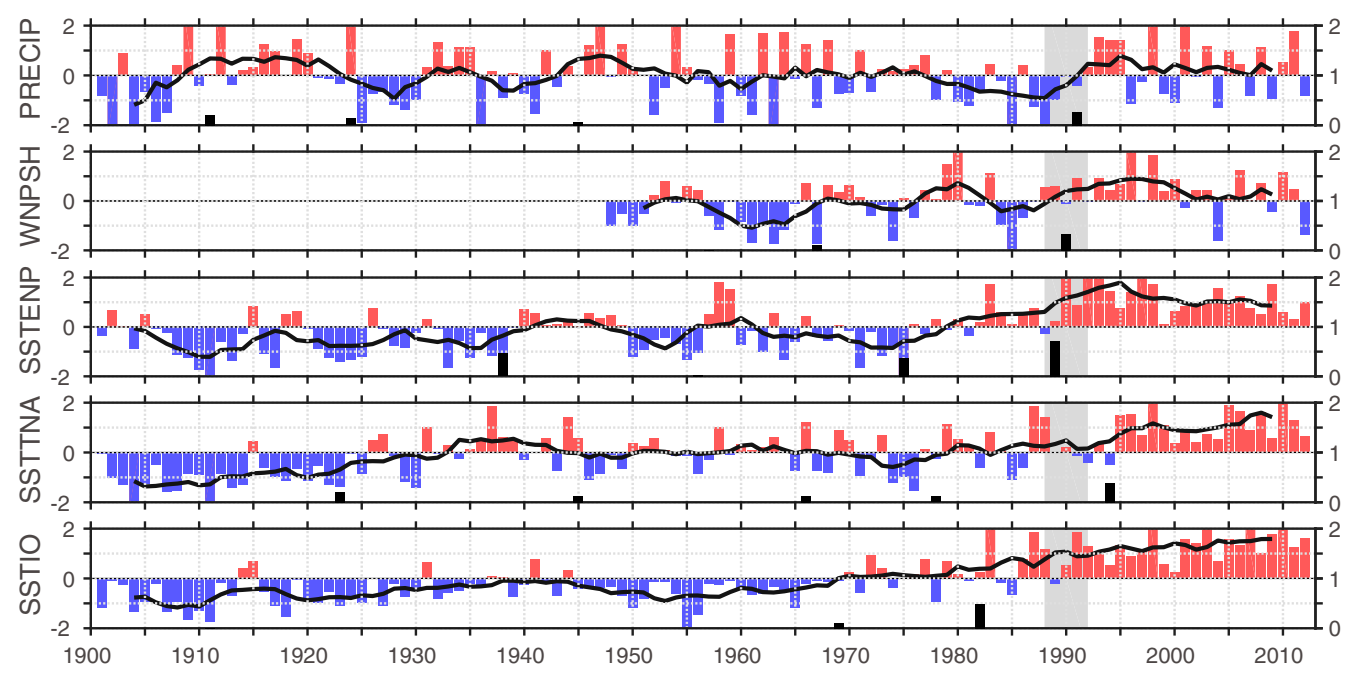

FIG. 5. From top to bottom, the normalized indices (bars) depict the precipitation of the $\mathrm{YHRV}\left(105^{\circ}-122^{\circ} \mathrm{E}\right.$, $20^{\circ}-33^{\circ} \mathrm{N}$ ), WNPSH (averaged $850-\mathrm{hPa}$ geopotential height over $\left.110^{\circ}-150^{\circ} \mathrm{E}, 15^{\circ}-25^{\circ} \mathrm{N}\right)$, SSTA in SENP $\left(120^{\circ}-\right.$ $\left.95^{\circ} \mathrm{W}, 5^{\circ}-30^{\circ} \mathrm{N}\right)$, TNA $\left(0^{\circ}-50^{\circ} \mathrm{W}, 0^{\circ}-15^{\circ} \mathrm{N}\right)$, and $\mathrm{IO}\left(50^{\circ}-100^{\circ} \mathrm{E}, 10^{\circ} \mathrm{S}-10^{\circ} \mathrm{N}\right)$ in June. The black line denotes the $7-\mathrm{yr}$ running mean of the normalized index. The black bars on the $X$ axes indicate that the indices experienced a significant abrupt change. The gray shading indicates the regime shift in the early 1990s. It denotes that the rainfall in the YHRV, WNPSH, and SENP-SST underwent an abrupt change during early 1990s. The $Y$ axes on the left and right denote the index and RSI, respectively. 
TABLE 2. The correlation coefficient among all the interdecadal variation (7-yr running mean) indices shown in Fig. 5. The definitions of indices were the same as in Fig. 5, and the correlations that are significant at the $10 \%$ level are in boldface type. An effective sample size (Quenouille 1952) was used in the significant test. The numbers inside and outside of the parentheses are the correlation coefficients with detrended and nondetrended SST, respectively.

\begin{tabular}{lccccc}
\hline \hline & Precipitation & WNPSH & SENP-SST & TNA-SST & IO-SST \\
\hline Precipitation & 1 & $\mathbf{0 . 6 1 ( 0 . 6 1 )}$ & $0.08(0.1)$ & $0.13(0.18)$ & $-0.1(-0.22)$ \\
WNPSH & & 1 & $\mathbf{0 . 5 9}(\mathbf{0 . 5 5})$ & $\mathbf{0 . 6}(0.34)$ & $0.39(0.06)$ \\
SENP-SST & & 1 & $\mathbf{0 . 8 1}(\mathbf{0 . 4 5})$ & $\mathbf{0 . 9 3 ( \mathbf { 0 . 7 6 } )}$ \\
TNA-SST & & & 1 & $\mathbf{0 . 7 8}(0.46)$ \\
IO-SST & & & & 1 \\
\hline
\end{tabular}

indicated that the SENP-SST led the WNPSH index for approximately 1-2 months (figure not shown). The coincidental abrupt changes in the WNPSH and SENPSST in the early 1990s (Table 2) as well as the lead-lag relationship between the WNPSH and SENP-SST suggested that the high (warm) SENP-SST was associated with an east-west overturning circulation anomaly in the Pacific (Fig. 4c) and possibly triggered the abrupt increase in the WNPSH in the early 1990s.

Figure 6a reveals the regression of the precipitation and 850-hPa wind anomalies onto the SENP-SST during 1980-2000. The period 1980-2000 was chosen such that the abrupt change in 1991-92 fell in the middle of this period (Fig. 5). A positive precipitation anomaly in South China and a low-level anticyclonic circulation anomaly in the WNP were clearly identified. The similarity between Figs. 6a and 2c indicates that the abovenormal mei-yu rainfall in the South China during IP3 was closely related with the SENP-SST. The connection of the SENP-SST, WNPSH, and mei-yu rainfall in the South China was further supported by the regression of the velocity potential and divergent wind onto the SENP-SST. An east-west overturning circulation anomaly in the subtropical North Pacific, an ascending in the subtropical eastern Pacific and descending in the subtropical western Pacific (Figs. 6b,c), was clearly seen. The east-west overturning circulation was still clearly identified in the multiregression when the IO-SST and TNA-SST were fixed (not shown). The regression analysis revealed that the effect of warm SENP-SST on the enhancement of the WNP subtropical high (WNPSH) was evident.

\section{Numerical experiments}

Figure 5 clearly shows that the abrupt change in the WNPSH in the early 1990s was synchronized with the change in the SENP-SST. The triggering effect of the SENP-SST on the abrupt increase of the WNPSH in the early 1990s was further investigated through numerical experiments. An atmospheric general circulation model called the simplified parameterizations primitive equation dynamics (SPEEDY) model (Molteni 2003) was used in this study. The SPEEDY model is efficient that had been widely and successfully used in the studies of large-scale dynamics and monsoon dynamics (e.g., Bracco et al. 2005; Chang et al. 2016; Kucharski et al. 2006; Sun et al. 2017). The AGCM contains eight vertical sigma levels with a horizontal resolution of T30. An AMIP-type experiment was conducted to investigate the specific SST in the WNPSH. Each experiment included 10-member simulations, with distinct initial conditions on 1 January of an arbitrary year obtained from a long-term simulation by forcing the AGCM with climatological SST. The model was integrated from 1979 to 2010. The design of the numerical experiment follows that of Lau and Nath $(1994,2000)$, and the details are listed in Table 3. The spatial pattern of SSTA prescribed to the model was shown in Fig. 2a. In the control run, the model was forced with climatological SST. In the SENP expt, the model was forced with the observed SENPSST in the ENP region and with climatological SST elsewhere. Other sensitivity runs, IO expt and TNA expt, were conducted to investigate the robustness of SENP expt. The IO expt and TNA expt runs were identical to the SENP expt run, except that the model was forced with the observed SSTs in the IO and TNA regions, respectively. The anomalous fields were calculated by subtracting the results of the SST experiments from the control experiment. A Student's $t$ test was applied to detect the signals. To investigate the effect of air-sea interaction, an air-sea coupled experiment (named SENP-cpl expt) followed by Lau and Nath (2000) was conducted. In SENP-cpl expt, the model was coupled to a slab ocean model with a mixed layer depth of $50 \mathrm{~m}$ over the WNP. Out of the WNP, the model was forced with the observed SSTs in the SENP and climatological SST conditions elsewhere. B. Wu et al. (2010) proposed that a passive warm SSTA (i.e., forced by atmosphere) will force an unrealistic (artificial) atmospheric response in the AMIP-type experiment. Therefore, the SSTA of the IO expt was limited in the tropical IO, and the warm SST in the WNP, which was 
(a) Regr: SENP \& Precip, 850hPa winds (1980-2000)

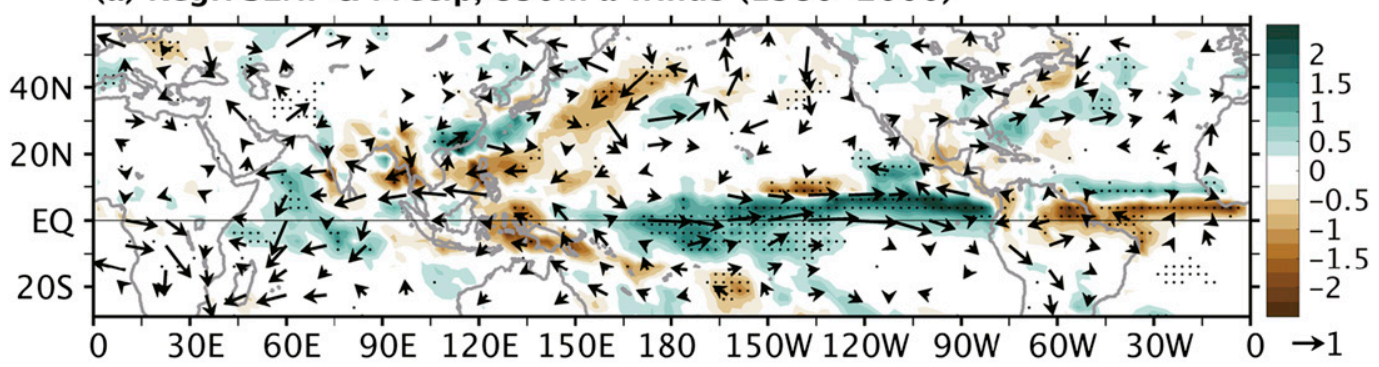

(b) Regr: SENP \& 850hPa velocity potential, div-winds (1980-2000)

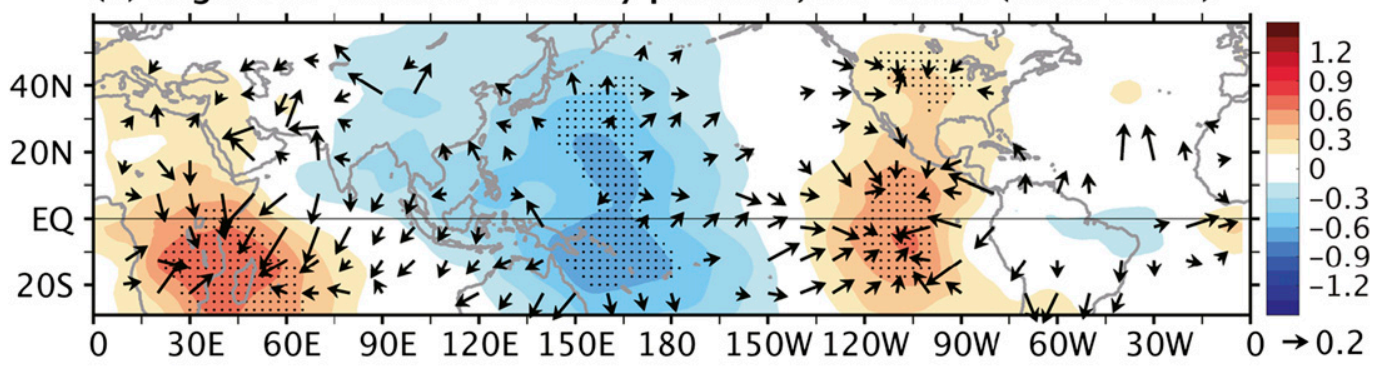

(c) Regr: SENP \& 200hPa velocity potential, div-winds (1980-2000)

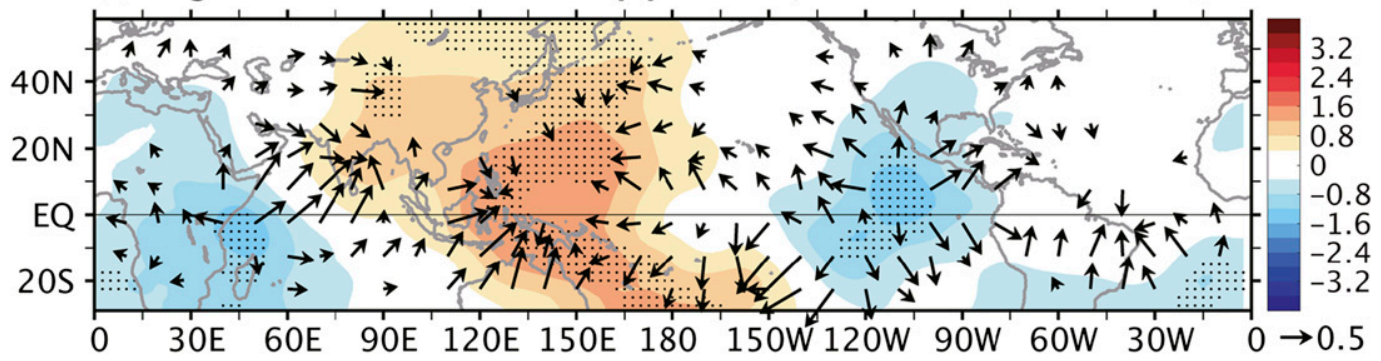

FIG. 6. Regression of the (a) precipitation and 850-hPa wind anomalies and (b) 850- and (c) 200-hPa velocity potential (shading; $10^{-6} \mathrm{~m}^{2} \mathrm{~s}^{-1}$ ) and divergent wind onto the SENP-SST in June during the abrupt change in 1991/92 associated with the period of 1980-2000. Shading with dots indicates significance exceeding the $95 \%$ confidence level. Only wind speeds exceeding $0.25,0.1$, and $0.2 \mathrm{~m} \mathrm{~s}^{-1}$ for (a)-(c), respectively, were plotted.

accompanied with a negative precipitation anomaly (Figs. 4a,b), was not included in the simulation.

\section{a. SENP-SST on triggering the abrupt increase of WNPSH}

Figure 7 depicts the simulated $850-\mathrm{hPa}$ streamfunction and $250-\mathrm{hPa}$ velocity potential anomalies during IP3 (1992-2002) for the SENP expt. A zonally distributed large-scale low-level anticyclone anomaly, from the coast of East Asia and Taiwan to the subtropical central Pacific, was clearly seen in the SENP expt. In the east of the anticyclone anomaly, an anomalous cyclone was observed. A comparison with the observations showed that the anticyclone and cyclone anomaly in the WNP and SENP, respectively, was realistically simulated (Figs. 4a and 7a). The velocity potential of $250-\mathrm{hPa}$ and divergent wind anomalies further indicated that the positive SENP-SSTA may generate an east-west overturning circulation anomaly (Fig. 7b), namely, an ascending and a descending anomaly in the SENP and WNP, respectively. The

TABLE 3. Design of numerical experiments.

\begin{tabular}{lccc}
\hline \hline \multicolumn{1}{c}{ Expt } & SSTA & $\begin{array}{c}\text { Air-sea } \\
\text { coupled }\end{array}$ & $\begin{array}{c}\text { Climatology- } \\
\text { SST }\end{array}$ \\
\hline CTL & None & None & Global \\
SENP & $120^{\circ}-95^{\circ} \mathrm{W}, 5^{\circ}-30^{\circ} \mathrm{N}$ & None & Elsewhere \\
IO & $50^{\circ}-100^{\circ} \mathrm{E}, 10^{\circ} \mathrm{S}-10^{\circ} \mathrm{N}$ & None & Elsewhere \\
TNA & $50^{\circ} \mathrm{W}-0^{\circ}, 0^{\circ}-15^{\circ} \mathrm{N}$ & None & Elsewhere \\
SENP-cpl & $120^{\circ}-95^{\circ} \mathrm{W}, 5^{\circ}-30^{\circ} \mathrm{N}$ & $110^{\circ}-160^{\circ} \mathrm{E}$, & Elsewhere \\
& & $0^{\circ}-30^{\circ} \mathrm{N}$ & \\
\hline
\end{tabular}


(a) ENP-exp IP3 850-uv \& streamfunction anomalies (June)

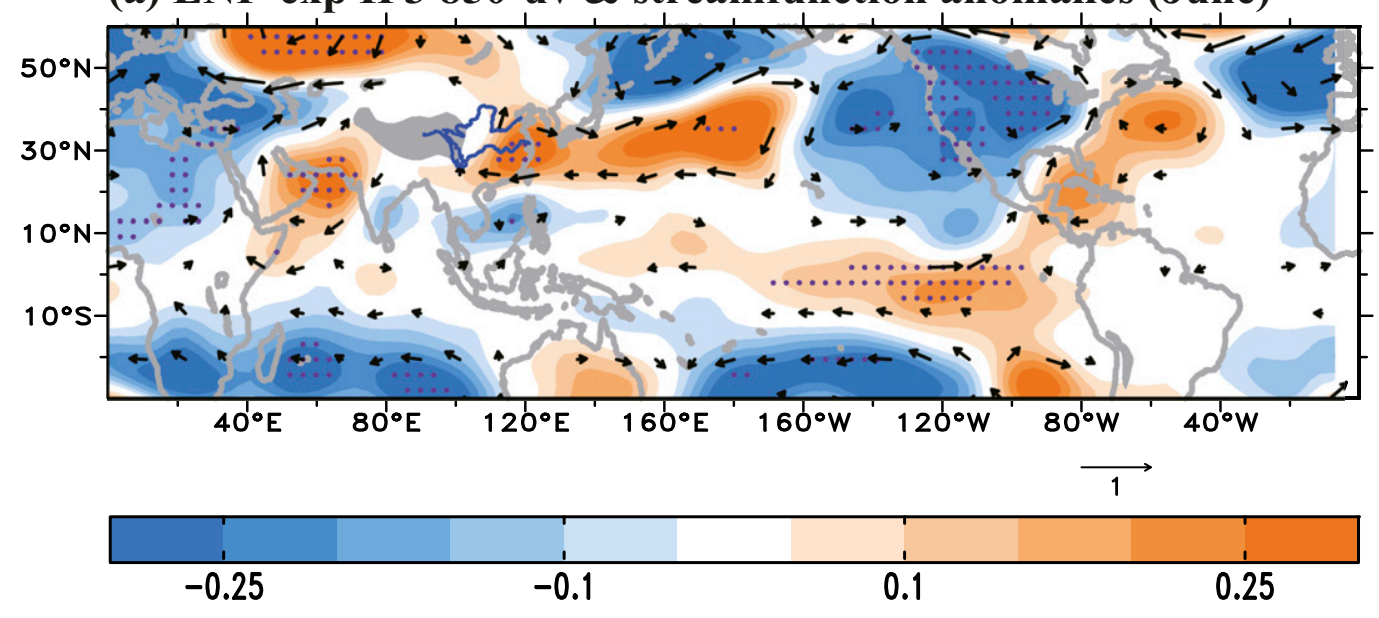

(b) ENP-exp IP3 250-UeVe \& velocity potential anomalies (June)

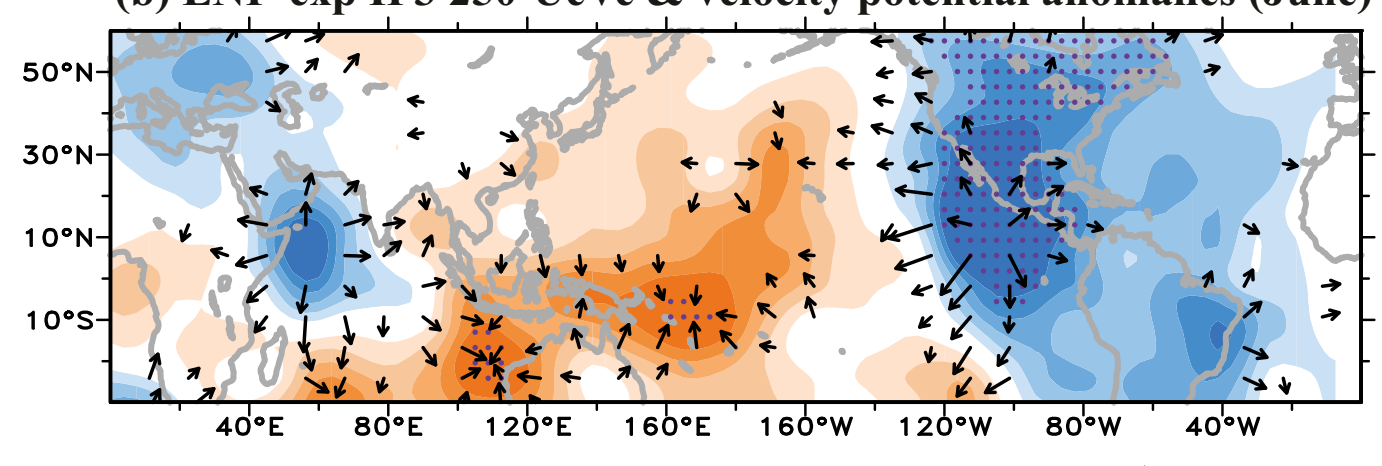

$\overrightarrow{0.25}$

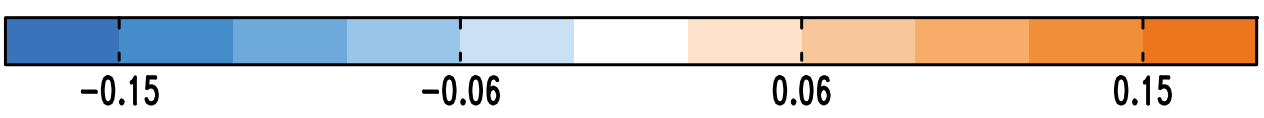

(c) 850 hPa PSI (110-140E, 15-35N)

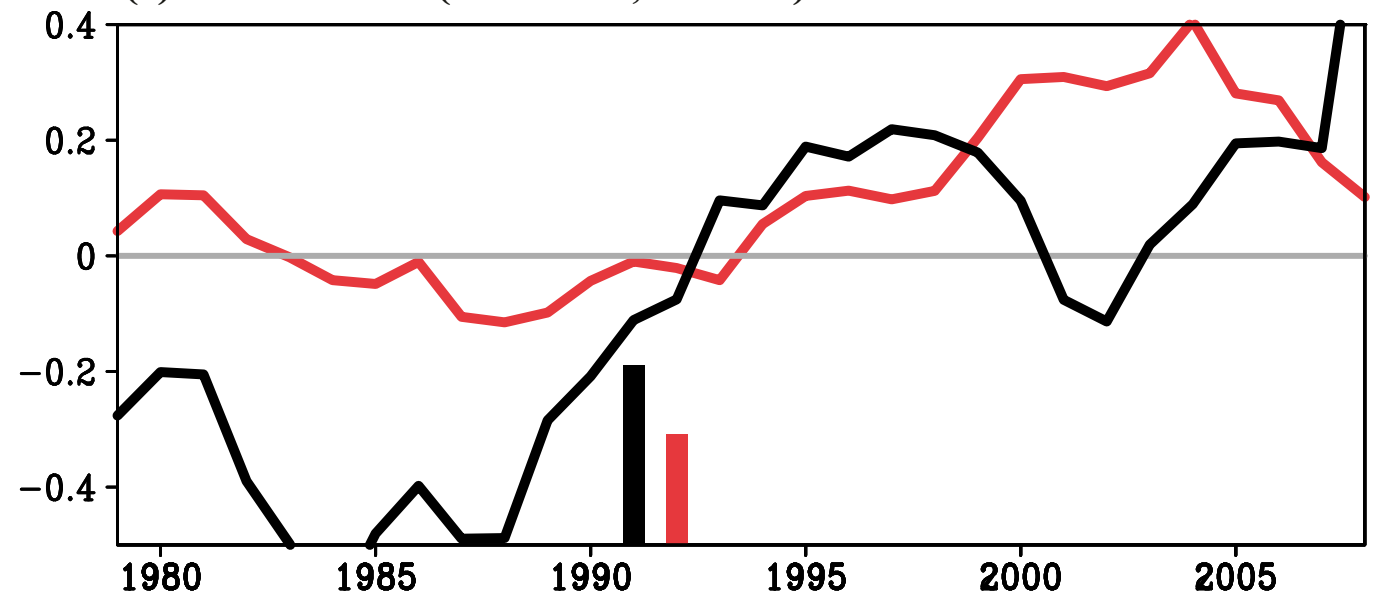

FIG. 7. The simulated (a) 850-hPa streamfunction and wind anomalies and (b) 250-hPa velocity potential and divergent wind anomalies in IP3 for the SENP expt. (c) Time series of the WNPSH index for the observations (black line) and SENP expt (red line). Shading marked with dots indicates the signal exceeding the $90 \%$ confidence level. Only wind speed larger than $0.1 \mathrm{~m} \mathrm{~s}^{-1}$ was plotted. The bars in the bottom of (c) show the RSI (Rodionov 2004) of WNPSH for the observation and simulation, respectively. The values of observed WNPSH have been multiplied by 0.25 for visualization. 


\section{(a) Observation}

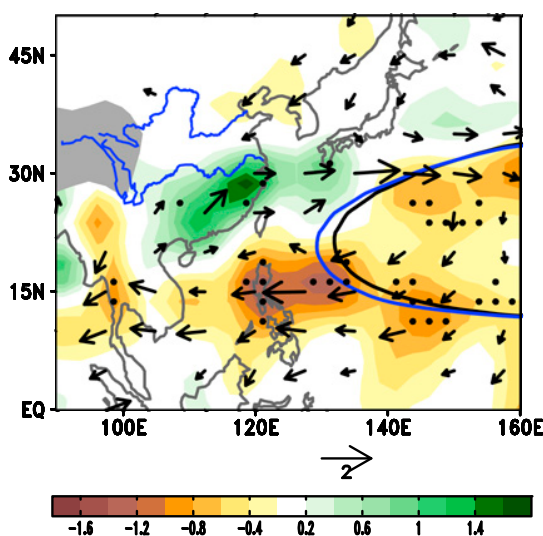

(b) ENP-cpl-exp Pr \& 850 wind

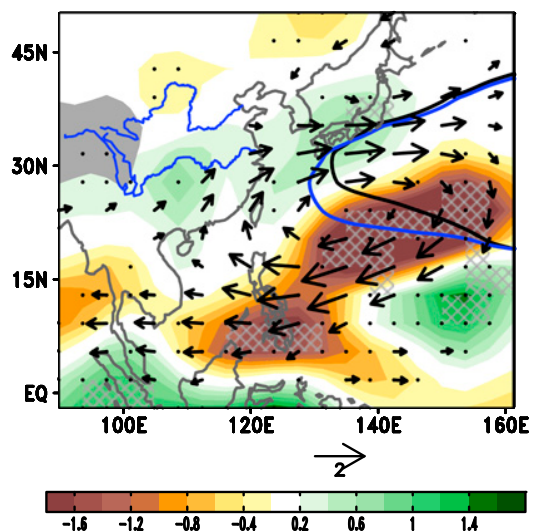

(c) ENP-cpl-exp 250 hPa PSI \& Div. wind

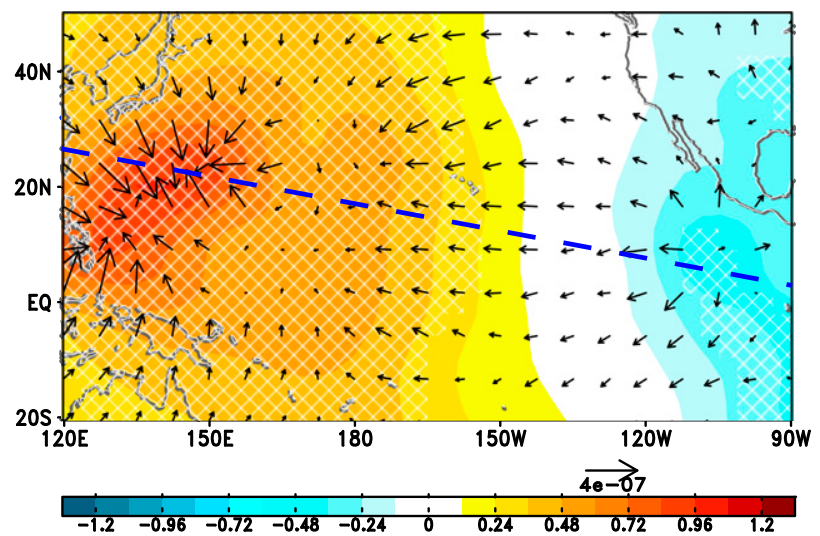

(d) ENP-cpl-exp Omega \& circlulation
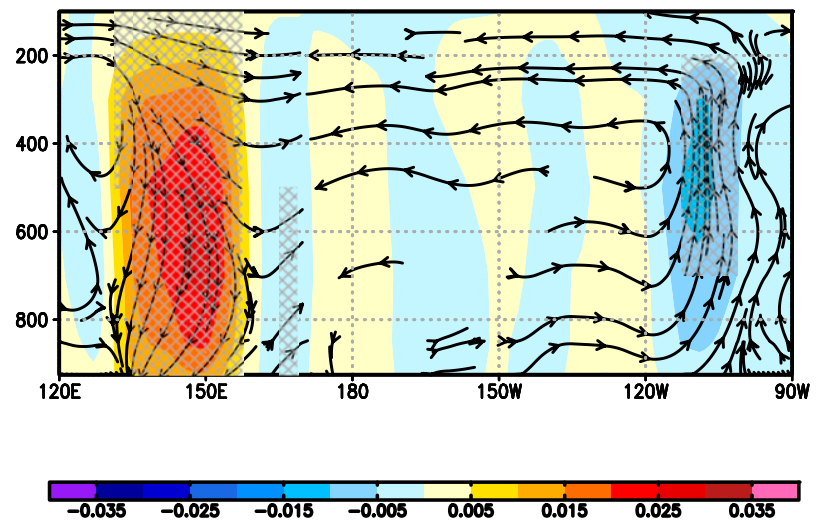

FIG. 8. Comparison of precipitation and 850-hPa wind anomalies between (a) observation and (b) simulation of SENP-cpl expt. Also shown are the simulated (c) 250-hPa velocity potential and divergent wind anomalies and (d) vertical cross section [along the blue dashed line in (c)] of vertical velocity (shading; $\mathrm{Pa} \mathrm{s}^{-1}$ ) and streamline anomalies for the SENP-cpl expt. The vertical velocity has been multiplied by -100 in the streamline for visualization. The blue and black lines in (a) and (b) denote the contour of $1525-\mathrm{m}$ geopotential height at $850 \mathrm{hPa}$ in the period of IP3 and climatology, respectively. The dots and cross hatching in (a) and (b) indicate the signal exceeding the $90 \%$ and $95 \%$ confidence level, respectively. The cross hatching in (c) and (d) indicates the signal exceeding the $95 \%$ confidence level.

descending branch in the WNP, although the descending position is more south than the observation, may have enhanced the WNPSH. The SENP-SST drives east-west overturning circulation anomaly was further supported a full AGCM of ECHAM5 (Roeckner et al. 2003) (not shown). That indicates the effect of SENP-SST on the enhancement of WNPSH was robust. A comparison of the time series of the observed and simulated WNPSH reveals that both experienced an about increase in the early 1990s (Fig. 7c), revealing the SENPSST may have triggered the abrupt increase in the WNPSH in the early 1990s.

\section{b. Effect of local air-sea interaction}

Whereas the abrupt increase of WNPSH in the early 1990s was realistically captured in the SENP expt, the simulated amplitude of WNPSH was underestimated, a general bias in AMIP-type simulations (Kang et al. 2002; Lee and Hsu 2013). Wang et al. (2000) proposed that except the remote SST-forcing, the local air-sea interaction plays a crucial role on the maintenance of WNPSH. The SST and low-level wind patterns in the WNP shown in Fig. 4a suggest that the local air-sea interaction might contribute to the maintenance of WNPSH. The effect of air-sea interaction on the maintenance of WNPSH was investigated by the SENPcpl experiment. Figure 8 shows the results of SENP-cpl experiment. As revealed by the figure, the low-level anticyclonic circulation anomaly and the rainfall pattern in the East Asia, a rainfall surplus and a decline in the South China and Philippine Seas, respectively, were realistically simulated (Figs. 8a,b). In particular, the 
(a) TNA-exp IP3 850-uv \& streamfunction anomalies (June)

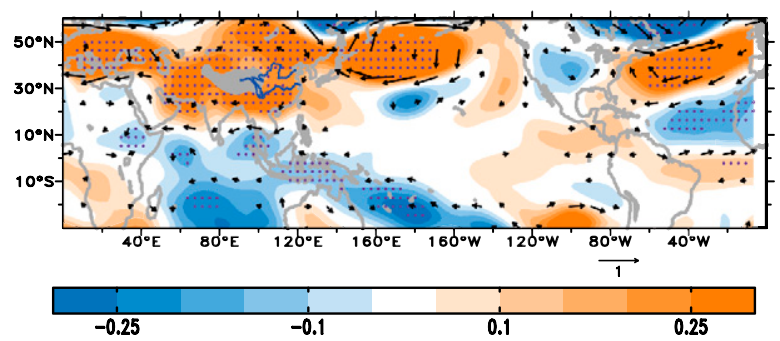

(b) TNA-exp IP3 250-UeVe \& velocity potential anomalies (June)

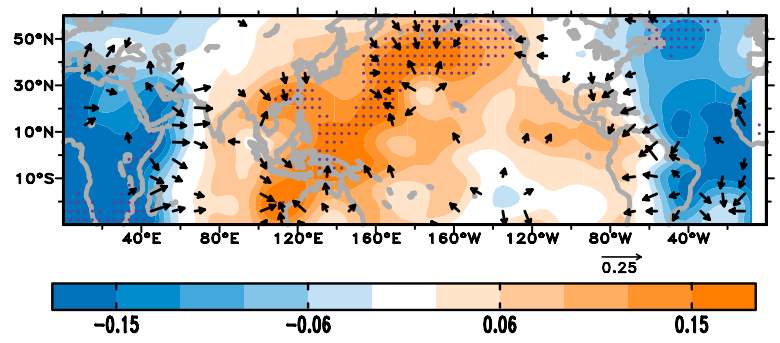

(c) TNA-exp 850 hPa PSI (110-140E, 15-35N)

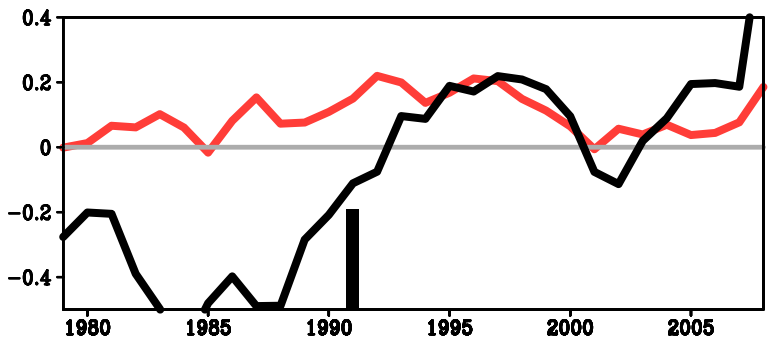

(d) IO-exp IP3 850-uv \& streamfunction anomalies (June)

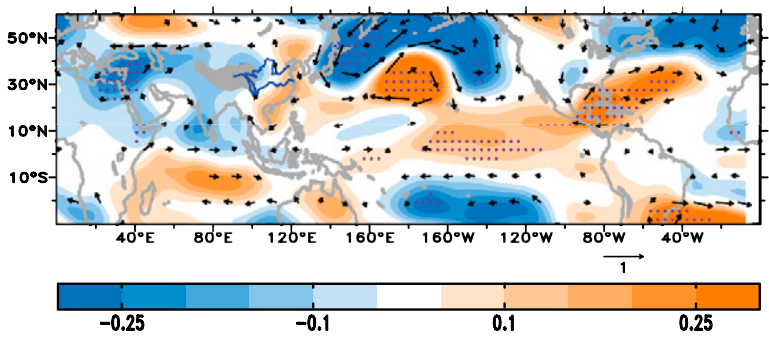

(e) IO-exp IP3 250-UeVe \& velocity potential anomalies (June)

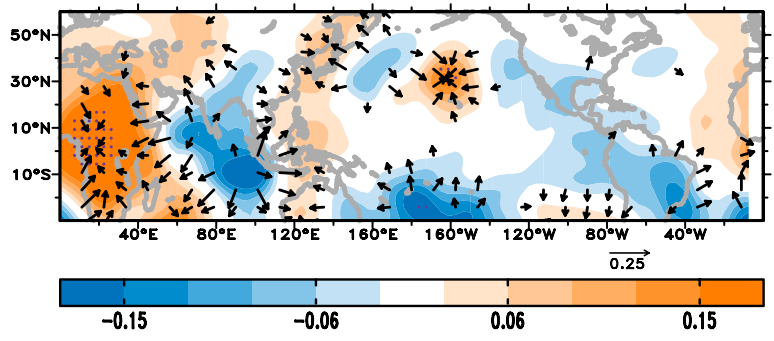

(f) IO-exp 850 hPa PSI (110-140E, 15-35N)

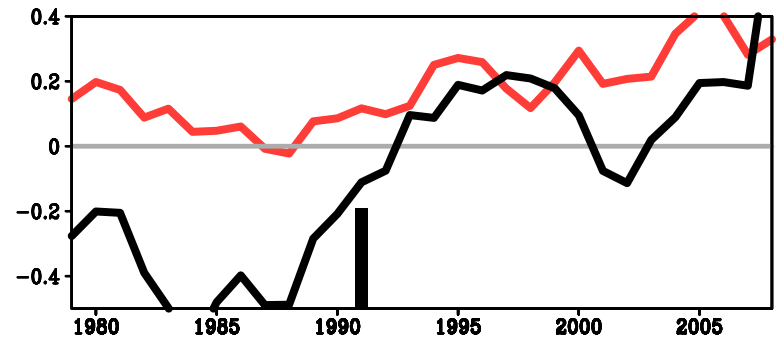

FIG. 9. As in Fig. 6, but (a)-(c) for the TNA expt and (d)-(f) for the IO expt.

east-west distributed upper-level velocity potential and divergent wind anomalies (Fig. 8c) and the overturning circulation anomalies in the Pacific (Fig. 8d) were successfully simulated. To further investigate how the local air-sea interaction enhances the WNPSH, we subtracted the simulation of the SENP-cpl expt from the SENP expt run. The results indicated that the enhanced WNPSH was associated with a southwest-northeast negative SSTA (figure not shown). This negative SSTA may force an anticyclonic anomaly, a Gill-type response to the SSTA, thus enhancing the WNPSH. Moreover, the negative SSTA was sustained by the anomalous northeasterly wind-induced latent heat, indicating that the local air-sea interaction is primarily determined by the wind-evaporation-SST feedback, which has been proposed by Wang et al. (2000) and Chang et al. (2016).

\section{c. Sensitivity experiments}

Figure 4a shows that the tropical SSTs in the Indian Ocean and Atlantic also exhibit significant warming in the IP3. The IO expt and TNA expt were conducted to investigate the robustness of the triggering effect of SENP-SST on the abrupt increase of WNPSH in the early 1990s. The effect of TNA-SST on the WNPSH was similar to that of the SENP-SST: The positive SSTA in the TNA generated a cross-basin east-west overturning circulation anomaly in the Atlantic Ocean and Pacific Ocean, an ascending (descending) anomaly in the Atlantic Ocean (western Pacific and Eurasian continent) (Fig. 9b), in which the descending anomaly in the western Pacific may have enhanced the WNPSH (Fig. 9a). Figure 9a also indicates that the TNA-SST generated an anomalous easterly wind in the North IO and an ascending (descending) anomaly in the western IO (western Pacific). This suggests that the effect of the TNA-SST on enhancing the WNPSH likely occurred through the IO basin and then through the NIO-WNP interaction (Chang et al. 2016). Notably, the TNA-SST was closely related with the AMO index $(r=0.76)$, and its effect on the large-scale circulation anomalies in the western Pacific was similar to that of AMO (e.g., Dong and Zhou 2014; Kucharski et al. 2016; Sun et al. 2017). The IO-SST also partially contributed to the 


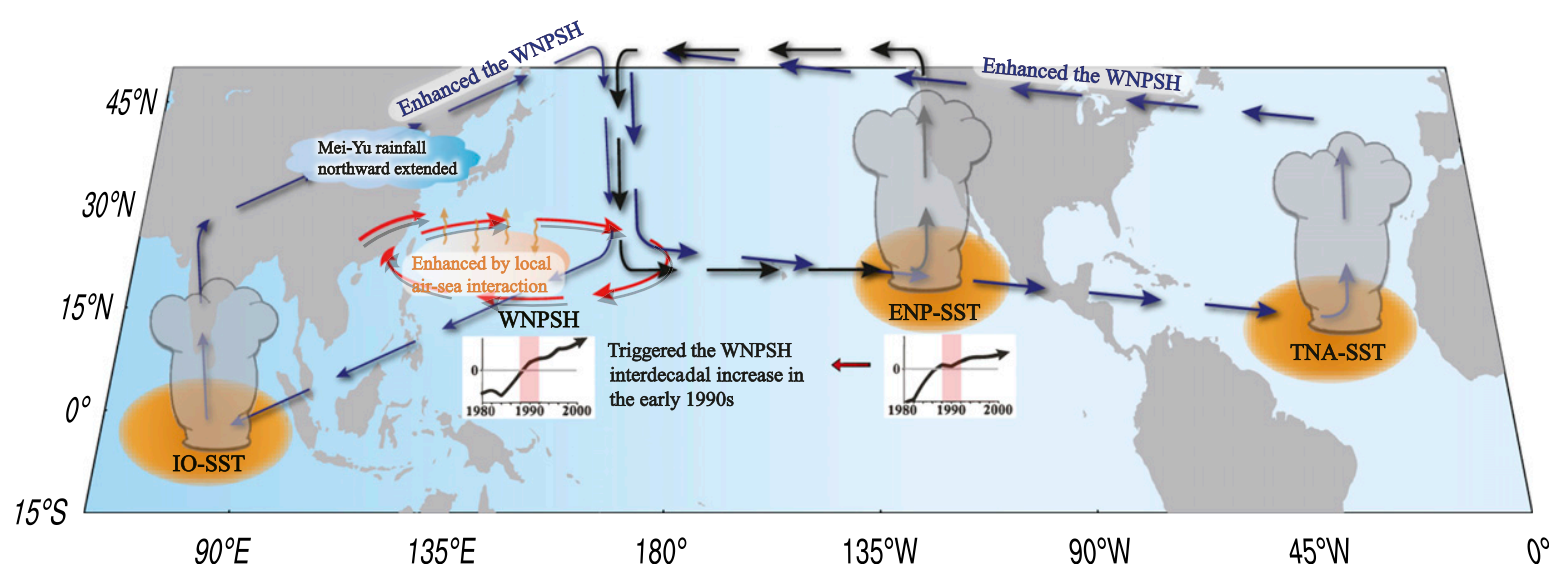

FIG. 10. Schematic diagram showing the physical mechanism of enhanced WNPSH during IP3.

enhancement of the WNPSH (Fig. 9d). In contrast to the SENP-SST and TNA-SST, the IO-SST forced a meridional-like overturning circulation anomaly, as reported in previous studies ( $\mathrm{R}$. Wu et al. 2010; Yang et al. 2007): an ascending and a descending anomaly in the southeastern IO and WNP, respectively (Fig. 9e).

Figure 9 depicts that the IO-SST and TNA-SST also partially contributed to the enhancement of WNPSH in IP3. However, the time series of the simulated WNPSH, consistent with the observation (Fig. 5), reveals that IOSST and TNA-SST increased and continuously contributed to the enhancement of the WNPSH since the early 1980s (Figs. 9c,f), a decade earlier than the abrupt increase of the observed WNPSH in the early 1990s. That indicates that the IO-SST and TNA-SST were not critical factors triggering the abrupt increase in the WNPSH in the early 1990s. Besides the IO-SST and TNA-SST, the possible effect of extratropical SSTs (Fig. 4a) in the North Atlantic $\left(35^{\circ}-55^{\circ} \mathrm{W}, 40^{\circ}-55^{\circ} \mathrm{N}\right)$ and North Pacific $\left(145^{\circ} \mathrm{E}-135^{\circ} \mathrm{W}, 45^{\circ}-60^{\circ} \mathrm{N}\right)$ on the WNPSH were investigated by the numerical experiments. No substantial influence on the enhanced and westward extension of the WNPSH was detected (not shown).

\section{Summary and discussion}

The mei-yu rainfall in South China exhibited an abrupt northward extension in the early 1990s. The northward extension significantly modified the dipole-like rainfall pattern in East Asia. The out-of-phase relationship between the rainfall in South China and that in the YHRV changed to an in-phase (monopole like) relationship. This study addressed the physical processes triggering the abrupt (rapid) change in the early 1990s and the physical processes responsible for the maintenance of the interdecadal change during 1992-2002. The schematic in Fig. 10 illustrates the following main results:

1) The mei-yu rainfall in South China in early summer (June) exhibited an abrupt change (above normal) and northward extension in the early 1990s. Observations revealed that this abrupt change was related with the enhanced and westward extension of the WNPSH, which concurrently experienced an abrupt change in the early 1990s.

2) Observations revealed that the SENP-SST and the WNPSH both exhibited an abrupt increase in the early 1990s. Observations and numerical experiments showed consistent results and indicated that the SENP-SST forced an east-west overturning circulation anomaly in the Pacific and that the subsidence in the western Pacific may have subsequently triggered an abrupt increase in the WNPSH. Numerical experiments revealed that the anomalous WNPSH was strengthened by the local air-sea interaction.

3) Sensitivity experiments revealed that the IO-SST and TNA-SST increased and continuously contributed to the enhancement of the WNPSH since the early 1980s, a decade earlier than the abrupt increase of observed WNPSH in the early 1990s. That indicates that the IO-SST and TNA-SST partially contributed to the enhancement of WNPSH in IP3 but were not the critical factors triggering the abrupt increase in the WNPSH in the early 1990s.

Notably, some of our results are different from those of the studies by Yim et al. (2014) and Zhang et al. (2017). These inconsistencies are primarily because of the differences in the time scale and season among the 


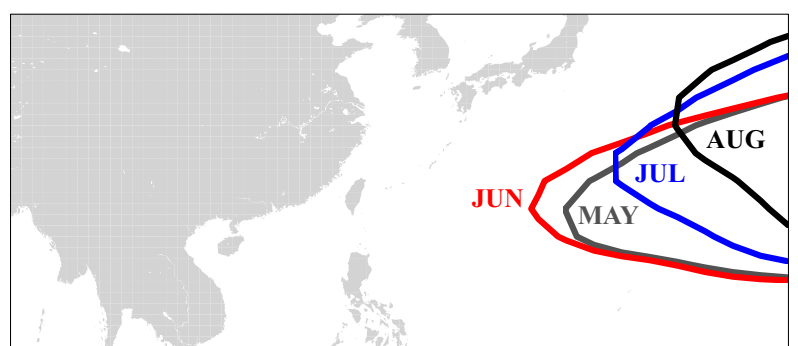

FIG. 11. Seasonal evolution of the ridge of WNPSH (contour of $1525-\mathrm{m}$ geopotential height at $850 \mathrm{hPa}$ ) of the climatological mean during 1979-2010.

studies. Yim et al. (2014) analyzed the effect of SST on the distinctive features of the interannual fluctuation of the mei-yu rainfall during different episodes (pre- and post-1995); Zhang et al. (2017) investigated the effect of
SST on the distinctions of the entire summer (JJA) rainfall between 1994-2002 and 1980-1993.

The interdecadal warming of SENP-SST in the early 1990s was initiated in late spring (not shown). The warm SENP-SST in May did not affect the northward extension of the mei-yu rainfall as it did in June (cf. Figs. 1a and $1 \mathrm{~b}$ ) because the SENP-SST-induced downward motion in the western Pacific was closely associated with the annual cycle of the WNPSH. The ridge of the WNPSH was located in the east of the WNP in May and extended westward to the WNP in June and moved northward to Japan in July-August (Fig. 11). Specifically, the SENP-SST-generated subsidence in the western Pacific exhibited an in-phase relationship with the ridge of the WNPSH, which may have optimally enhanced the WNPSH. In May, the ridge of the WNPSH was

(a) Precipitation \& wind anomalies in 1946-1955 (June)

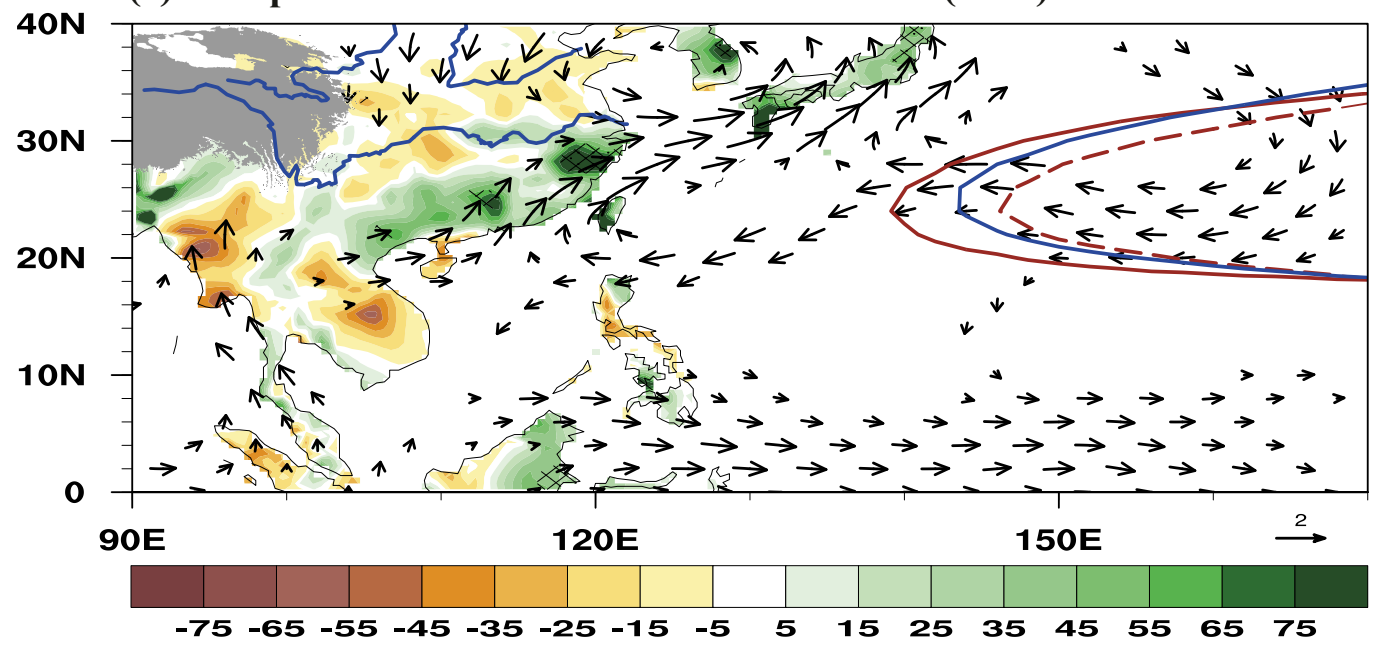

(b) SST anomaly in 1946-1955 (June)

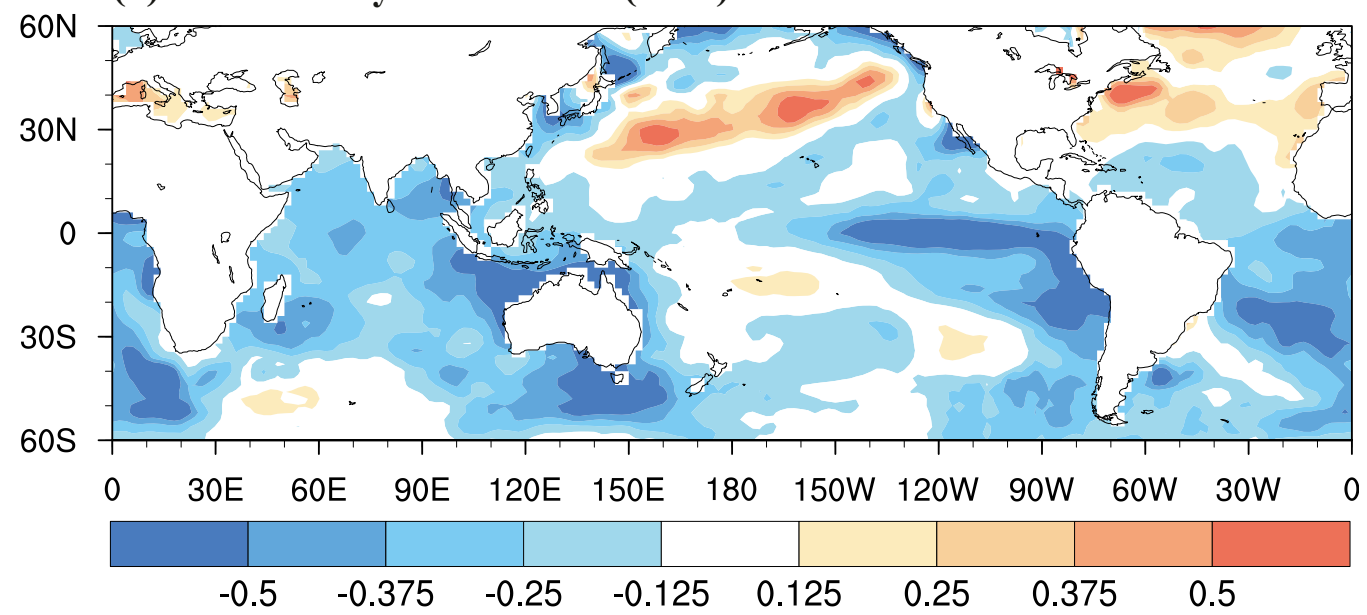

FIG. 12. (a) As in Fig. 2c, but for the background state (1946-55) according to the abrupt northward extension of meiyu rainfall in 1945; the solid and dashed red lines indicate the 1525-m geopotential height in the period 1946-55 and 1936-45, respectively, and the blue line indicates that for the climatological mean. (b) Similar to (a), but for the SSTA. 
located far from the WNP and the annual cycle of the intertropical convergence zone in the eastern Pacific did not yet extend northward to SENP; therefore, the SENP-SST did not force a strong anomalous anticyclone in the WNP in this month. Because of data limitations, the interdecadal change in the mei-yu rainfall in the South China was investigated for periods since 1950. Reanalyzing long-term CRU rainfall data and NOAA-CIRES twentieth-century reanalysis (V2c) (Compo et al. 2011) revealed that the meiyu rainfall in the South China also exhibited an abrupt interdecadal northward extension in approximately 1945 (Fig. 5). We compared the abrupt change in 1945 with the abrupt change in the early 1990s. The WNPSH also exhibited an abrupt enhancement and westward extension in approximately 1945 (Fig. 12a), indicating that the WNPSH played a dominant role in the northward extension of meiyu rainfall in South China for the past decades. In contrast to the 1990s, a La Niña-like negative SSTA in the equatorial central-eastern Pacific, instead of the warm SST in the SENP, was identified during 1946-55 (Fig. 12b). The La Niña-like SSTA forced a pair of anticyclonic anomalies, a Gill-type response to the SSTA, in the off-equator regions over the western Pacific, which contributed substantially to the enhancement and westward extension of the WNPSH. These results suggest that the effect of SENP-SST on the WNPSH and the abrupt change of mei-yu rainfall in South China became pronounced in recent decades.

This study mainly analyzed the role of high (warm) subtropical SSTs in the SENP in triggering the abrupt enhancement of the WNPSH during IP3. The physical process responsible for warming in the SENP, which is beyond the scope of this study, is not discussed in the text. Observation reveals that the SENP-SST was correlated with the north pole of the Pacific meridional mode (Chiang and Vimont 2004), particularly during IP3 $(r=0.52)$. Additionally, persistent warming in the SENP was identified during 2013-15 (Di Lorenzo and Mantua 2016). The recent warming in the SENP was found to substantially modify the tropical cyclonic activity either in the WNP (Hong et al. 2016) or in the SENP (Murakami et al. 2017). Thus, the physical process responsible for the persistent warming in the SENP warrants further investigation.

Acknowledgments. We are grateful to three anonymous reviewers for their valuable comments. The observational atmospheric and oceanic data used in this study are from the NOAA Earth System Research Laboratory, NCEP/NCAR, ECMWF/ERA-40, and Met Office Hadley Center. Precipitation data are from CRU TS 3.20; GPCP, version 2.2; and APHRODITE. The NOAA-CIRES Twentieth Century Reanalysis Project, version 2c, used resources of the National Energy
Research Scientific Computing Center managed by Lawrence Berkeley National Laboratory, which is supported by the Office of Science of the U.S. Department of Energy under Contract DE-AC02-05CH11231. Simulation data are created from ICTP AGCM (SPEEDY) and are accessible online (https://rive.google.com/drive/folders/ 1dFcBN4f2F5BWiS6OsJm3GSnir-zH3ru7). This study was supported by the Ministry of Science and Technology, Taiwan, under Grants 103-2111-M845-002, 104-2111-M845-002, 104-26211-M865-001, and 107-2111-M-845-001. This paper was edited by Wallace Academic Editing.

\section{REFERENCES}

Adler, R. F., and Coauthors, 2003: The Version-2 Global Precipitation Climatology Project (GPCP) monthly precipitation analysis (1979-present). J. Hydrometeor., 4, 1147-1167, https://doi.org/ 10.1175/1525-7541(2003)004<1147:TVGPCP $>2.0$. CO 2 .

Barry, D., and J. A. Hartigan, 1993: A Bayesian analysis for change point problems. J. Amer. Stat. Assoc., 88, 309-319, https:// doi.org/10.2307/2290726.

Bracco, A., F. Kucharski, F. Molteni, W. Hazeleger, and C. Severijns, 2005: Internal and forced modes of variability in the Indian Ocean. Geophys. Res. Lett., 32, L12707, https:// doi.org/10.1029/2005GL023154.

Chan, J. C. L., and W. Zhou, 2005: PDO, ENSO and the early summer monsoon rainfall over south China. Geophys. Res. Lett., 32, L08810, https://doi.org/10.1029/ 2004GL022015.

Chang, C. P., Y. Zhang, and T. Li, 2000: Interannual and interdecadal variations of the East Asian summer monsoon and tropical Pacific SSTs. Part I: Roles of the subtropical ridge. J. Climate, 13, 4310-4325, https://doi.org/10.1175/1520-0442(2000) 013<4310:IAIVOT>2.0.CO;2.

Chang, T. C., H. H. Hsu, and C. C. Hong, 2016: Enhanced influences of tropical Atlantic SST on WNP-NIO atmosphereocean coupling since the early 1980s. J. Climate, 29, 6509-6525, https://doi.org/10.1175/JCLI-D-15-0807.1.

Chiang, J. C., and D. J. Vimont, 2004: Analogous Pacific and Atlantic meridional modes of tropical atmosphere-ocean variability. J. Climate, 17, 4143-4158, https://doi.org/10.1175/ JCLI4953.1.

Compo, G. P., and Coauthors, 2011: The Twentieth Century Reanalysis Project. Quart. J. Roy. Meteor. Soc., 137, 1-28, https:// doi.org/10.1002/qj.776.

Di Lorenzo, E., and N. Mantua, 2016: Multi-year persistence of the 2014/15 North Pacific marine heatwave. Nat. Climate Change, 6, 1042-1047, https://doi.org/10.1038/nclimate3082.

Ding, Y., Z. Wang, and Y. Sun, 2008: Inter-decadal variation of the summer precipitation in East China and its association with decreasing Asian summer monsoon. Part I: Observed evidences. Int. J. Climatol., 28, 1139-1162, https://doi.org/10.1002/ joc. 1615 .

Dong, L., and T. Zhou, 2014: The formation of the recent cooling in the easterntropical Pacific Ocean and the associated climate impacts: A competition of global warming, IPO, and AMO. J. Geophys. Res., 119, $11272-11$ 287, https://doi.org/10.1002/ 2013JD021395.

Duchon, C. E., 1979: Lanczos filtering in one and two dimensions. J. Appl. Meteor., 18, 1016-1022, https://doi.org/10.1175/ 1520-0450(1979)018<1016:LFIOAT > 2.0.CO;2. 
Enfield, D. B., A. M. Mestas-Nuñez, and P. J. Trimble, 2001: The Atlantic multidecadal oscillation and its relation to rainfall and river flows in the continental U.S. Geophys. Res. Lett., 28, 2077-2080, https://doi.org/10.1029/2000GL012745.

Erdman, C., and J. W. Emerson, 2008: bcp: An R package for performing a Bayesian analysis of change point problems. J. Stat. Software, 23 (3), 1-13, https://doi.org/10.18637/jss.v023.i03.

He, C., and T. Zhou, 2014: The two interannual variability modes of the western North Pacific subtropical high simulated by 28 CMIP5-AMIP models. Climate Dyn., 43, 2455-2469, https:// doi.org/10.1007/s00382-014-2068-x.

Hong, C.-C., T.-C. Chang, and H.-H. Hsu, 2014: Enhanced relationship between the tropical Atlantic SST and the summertime western North Pacific subtropical high after the early 1980. J. Geophys. Res. Atmos., 119, 3715-3722, https://doi.org/ 10.1002/2013JD021394.

- M.-Y. Lee, H.-H. Hsu, N.-H. Lin, and B.-J. Tsuang, 2015: Tropical SST forcing on the anomalous WNP subtropical high during July-August 2010 and the record-high SST in the tropical Atlantic. Climate Dyn., 45, 633-650, https://doi.org/ 10.1007/s00382-014-2275-5.

,,--- , and T.-C. Chang, 2016: Compounding factors causing the unusual absence of tropical cyclones in the western North Pacific during August 2014. J. Geophys. Res. Atmos., 121, 9964-9976, https://doi.org/10.1002/2016JD025507.

Huffman, G. J., R. F. Adler, D. T. Bolvin, and G. Gu, 2009: Improving the global precipitation record: GPCP version 2.1. Geophys. Res. Lett., 36, L17808, https://doi.org/10.1029/ 2009GL040000.

Jones, P. D., and I. C. Harris, 2013: CRU TS3. 20: Climatic Research Unit (CRU) Time-Series (TS) Version 3.20 of High Resolution Gridded Data of Month-by-Month Variation in Climate (January 1901-December 2011). NCAS British Atmospheric Data Centre, accessed 1 November 2013, http://catalogue.ceda.ac.uk/ uuid/2949a8a25b375c9e323c53f6b6cb2a3a.

Kang, I.-S., and Coauthors, 2002: Intercomparison of the climatological variations of Asian summer monsoon precipitation simulated by 10 GCMs. Climate Dyn., 19, 383-395, https:// doi.org/10.1007/s00382-002-0245-9.

Kucharski, F., F. Molteni, and A. Bracco, 2006: Decadal interactions between the western tropical Pacific and the North Atlantic Oscillation. Climate Dyn., 26, 79-91, https://doi.org/ 10.1007/s00382-005-0085-5.

— , and Coauthors, 2016: The teleconnection of the tropical Atlantic to Indo-Pacific sea surface temperatures on interannual to centennial time scales: A review of recent findings. Atmosphere, 7, 29, https://doi.org/10.3390/atmos7020029.

Kwon, M., J. G. Jhun, and K. J. Ha, 2007: Decadal change in east Asian summer monsoon circulation in the mid-1990s. Geophys. Res. Lett., 34, L21706, https://doi.org/10.1029/2007GL031977.

Lau, N. C., and M. J. Nath, 1994: A modeling study of the relative roles of tropical and extratropical SST anomalies in the variability of the global atmosphere-ocean system. J. Climate, 7,1184-1207, https://doi.org/10.1175/1520-0442(1994) 007<1184:AMSOTR>2.0.CO;2.

— Asian-Australian monsoons as simulated in GCM experiments. J. Climate, 13, 4287-4309, https://doi.org/10.1175/1520-0442(2000) 013<4287:IOEOTV>2.0.CO;2.

Lee, M.-Y. and H.-H. Hsu, 2013: Identification of the EurasianPacific multidecadal oscillation and its relationship with AMO. J. Climate, 26, 8139-8153, https://doi.org/10.1175/ JCLI-D-13-00041.1.
Li, W., L. Li, M. Ting, and Y. Liu, 2012: Intensification of Northern Hemisphere subtropical highs in a warming climate. Nat. Geosci., 5, 830-834, https://doi.org/10.1038/ngeo1590.

Ma, Z., 2007: The interdecadal trend and shift of dry/wet over the central part of North China and their relationship to the Pacific decadal oscillation (PDO). Chin. Sci. Bull., 52, 2130-2139, https://doi.org/10.1007/s11434-007-0284-z.

Molteni, F., 2003: Atmospheric simulations using a GCM with simplified physical parametrizations. I: Model climatology and variability in multi-decadal experiments. Climate Dyn., 20, 175-191, https://doi.org/10.1007/s00382-002-0268-2.

Murakami, H., and Coauthors, 2017: Dominant role of subtropical Pacific warming in extreme eastern Pacific hurricane seasons: 2015 and the future. J. Climate, 30, 243-264, https://doi.org/ 10.1175/JCLI-D-16-0424.1.

Nitta, T., 1987: Convective activities in the tropical western Pacific and their impact on the northern hemisphere summer circulation. J. Meteor. Soc. Japan, 65, 373-390, https://doi.org/ 10.2151/jmsj1965.65.3_373.

Qian, C., and T. Zhou, 2014: Multidecadal variability of north China aridity and its relationship to PDO during 1900-2010. J. Climate, 27, 1210-1222, https://doi.org/10.1175/JCLI-D-13-00235.1.

Quenouille, M. H., 1952: Associated Measurements. Butterworths, 242 pp.

Rayner, N., D. E. Parker, E. B. Horton, C. K. Folland, L. V. Alexander, D. P. Rowell, E. C. Kent, and A. Kaplan, 2003: Global analyses of sea surface temperature, sea ice, and night marine air temperature since the late nineteenth century. Geophys. Res., 108, 4407, https://doi.org/10.1029/ 2002JD002670.

Rodionov, S. N., 2004: A sequential algorithm for testing climate regime shifts. Geophys. Res. Lett., 31, L09204, https://doi.org/ 10.1029/2004GL019448.

Roeckner, E., and Coauthors, 2003: The atmospheric general circulation model ECHAM5. Part I: Model description. Max Planck Institute for Meteorology Rep. 349, 127 pp., http:// hdl.handle.net/11858/00-001M-0000-0012-0144-5.

Sun, C., F. Kucharski, J. Li, F.-F. Jin, I.-S. Kang, and R. Ding., 2017: Western tropical Pacific multidecadal variability forced by the Atlantic multidecadal oscillation. Nat. Commun., 8, 15998, https://doi.org/10.1038/ncomms15998.

Tao, S. Y., and L. Chen, 1987: A review of recent research on the East Asian summer monsoon in China. Monsoon Meteorology, C. P. Chang and T. N. Krishnamurti, Eds., Oxford University Press, 60-92.

Uppala, S. M., and Coauthors, 2005: The ERA-40 Re-Analysis. Quart. J. Roy. Meteor. Soc., 131, 2961-3012, https://doi.org/ 10.1256/qj.04.176.

Wang, B., and H. Lin, 2002: Rainy season of the Asian-Pacific summer monsoon. J. Climate, 15, 386-398, https://doi.org/ 10.1175/1520-0442(2002)015<0386:RSOTAP $>2.0 . C O ; 2$

- - R. Wu, and X. Fu, 2000: Pacific-East Asian teleconnection: How does ENSO affect East Asian climate? J. Climate, 13, 1517-1536, https://doi.org/10.1175/1520-0442(2000) $013<1517$ :PEATHD $>2.0$. CO 2 .

Wu, B., T. Li, and T. Zhou, 2010: Relative contributions of the Indian Ocean and local SST anomalies to the maintenance of the western North Pacific anomalous anticyclone during the El Niño decaying summer. J. Climate, 23, 2974-2986, https:// doi.org/10.1175/2010JCLI3300.1.

Wu, R., Z. Wen, S. Yang, and Y. Li, 2010: An interdecadal change in southern China summer rainfall around 1992/93. J. Climate, 23, 2389-2403, https://doi.org/10.1175/2009JCLI3336.1. 
Xie, S., K. Hu, J. Hafner, H. Tokinaga, Y. Du, G. Huang, and T. Sampe, 2009: Indian Ocean capacitor effect on Indo-western Pacific climate during the summer following El Niño. J. Climate, 22, 730-747, https://doi.org/10.1175/2008JCLI2544.1.

_, Y. Du, G. Huang, X. Zheng, H. Tokinaga, K. Hu, and Q. Liu, 2010: Decadal shift in El Niño influences on Indo-western Pacific and East Asian climate in the 1970s. J. Climate, 23, 3352-3368, https://doi.org/10.1175/2010JCLI3429.1.

Xin, X., R. Yu, T. Zhou, and B. Wang, 2006: Drought in late spring of South China in recent decades. J. Climate, 19, 3197-3206, https://doi.org/10.1175/JCLI3794.1.

Yang, J., Q. Liu, S.-P. Xie, Z. Liu, and L. Wu, 2007: Impact of the Indian Ocean SST basin mode on the Asian summer monsoon. Geophys. Res. Lett., 34, L02708, https://doi.org/10.1029/ 2006 GL028571.

Yatagai, A., K. Kamiguchi, O. Arakawa, A. Hamada, N. Yasutomi, and A. Kitoh, 2012: APHRODITE: Constructing a long-term daily gridded precipitation dataset for Asia based on a dense network of rain gauges. Bull. Amer. Meteor. Soc., 93, 14011415, https://doi.org/10.1175/BAMS-D-11-00122.1.

Yim, S. Y., J.-G. Jhun, and S.-W. Yeh, 2008a: Decadal change in the relationship between east Asian-western North $\mathrm{Pa}$ cific summer monsoons and ENSO in the mid-1990s. Geophys. Res. Lett., 35, L20711, https://doi.org/10.1029/ 2008GL035751.

- S. W. Yeh, R. Wu, and J. G. Jhun, 2008b: The influence of ENSO on decadal variations in the relationship between the East Asian and western North Pacific summer monsoons. J. Climate, 21, 3165-3179, https://doi.org/10.1175/ 2007JCLI1948.1.

- B. Wang, and M. Kwon, 2014: Interdecadal change of the controlling mechanisms for East Asian early summer rainfall variation around the mid-1990s. Climate Dyn., 42, 1325-1333, https://doi.org/10.1007/s00382-013-1760-6.

Yu, R., and T. Zhou, 2007: Seasonality and three-dimensional structure of interdecadal change in the East Asian monsoon. J. Climate, 20, 5344-5355, https://doi.org/10.1175/ 2007JCLI1559.1.

Zhang, H., Z. Wen, R. Wu, Z. Chen, and Y. Guo, 2017: Interdecadal changes in the East Asian summer monsoon and associations with sea surface temperature anomaly in the south Indian Ocean. Climate Dyn., 48, 1125-1139, https://doi.org/ 10.1007/s00382-016-3131-6.

,,,--- X. Li, and R. Chen, 2018: An inter-decadal increase in summer sea level pressure over the Mongolian region around the early 1990s. Climate Dyn., 49,1-14, https://doi.org/ 10.1007/s00382-018-4228-x.

Zhou, T., and Coauthors, 2009: Why the western Pacific subtropical high has extended westward since the late 1970s. J. Climate, 22, 2199-2215, https://doi.org/10.1175/2008JCLI2527.1.

Zhu, Z., T. Li, and J. He, 2014: Out-of-phase relationship between boreal spring and summer decadal rainfall changes in southern China. J. Climate, 27, 1083-1099, https://doi.org/ 10.1175/JCLI-D-13-00180.1. 